\title{
Desktop Fabrication of Strong Poly (Lactic Acid) Parts: FFF Process Parameters Tuning
}

\author{
Vladimir E. Kuznetsov ${ }^{1, * \mathbb{C}}$, Azamat G. Tavitov ${ }^{1}$, Oleg D. Urzhumtsev ${ }^{1}$, Artem A. Korotkov ${ }^{1}$, \\ Sergey V. Solodov ${ }^{2}$ and Alexey N. Solonin ${ }^{1}$ \\ 1 Department of Physical Metallurgy of Non-Ferrous Metals, National University of Science and Technology \\ “MISIS", Leninskiy Prospekt 4, NUST MISIS, 119049 Moscow, Russia \\ 2 Departament of Automated Control Systems, National University of Science and Technology "MISIS", \\ Leninskiy Prospekt 4, NUST MISIS, 119049 Moscow, Russia \\ * Correspondence: kuznetsovve@misis.ru; Tel.: +7-926-231-2760
}

Received: 10 June 2019; Accepted: 25 June 2019; Published: 27 June 2019

\begin{abstract}
The current study aims to evaluate the possibilities to increase part strength by optimizing the Fused Filament Fabrication (FFF) process parameters. Five different CAD models of parts with the same coupling dimensions but of different shape inherited from a recent study were converted into test samples with Ultimaker $23 \mathrm{D}$ printer. The main measure of success was the sample strength, defined as the load at which the first crack in the stressed area of the part appeared. Three different modifications to the FFF process with verified positive effect on interlayer bonding were applied. The first modification included raising the extrusion temperature and disabling printed part cooling. The second modification consisted of reduction in the layer thickness. The third modification combined the effects of the first and the second ones. For four out of five shapes tested the applied process modifications resulted in significant strengthening of the part. The shape that exhibited the best results was subject to further research by creating special printing mode. The mode included fine-tuning of three technological parameters on different stages of the part fabrication. As a result it was possible to increase the part strength by $108 \%$ only by tuning printing parameters of the best shape designed with increasing its weight by $8 \%$.
\end{abstract}

Keywords: fused filament fabrication; fused deposition modeling; interlayer bonding; technology optimization

\section{Introduction}

Additive manufacturing ( $\mathrm{AM}$ ) has been primarily considered as rapid prototyping technology for 10 to 15 years since its appearance [1-7] in the mid-1980s. In other words, AM was mostly used for creating mockups of new products or building functional prototypes. Since the mid-1990s, the rapid tooling concept started to emerge. Rapid tooling is an application of AM to produce tooling for conventional manufacturing processes such as casting, molding, and forming [8-20]. The next evolutionary step in AM has become rapid manufacturing: 3D printers are used for immediate manufacturing of the ultimate product [21-24] or spare parts [25]. In last several years the most prominent trend in AM development is increasing the availability and affordability of machines and supplies. There are relatively affordable solutions emerging for vat photopolymerization [26-28] as well as powder bed fusion [29], but the major share of affordable desktop machines operate on the material extrusion principle. The most widespread material extrusion AM technology is Fused Filament Fabrication (FFF). It uses polymer supplied in the form of filament that is melted, extruded, and deposited in layers. The FFF technology evolved fast thanks to the open source nature of the RepRap [30,31] project. Along with broad distribution and drastic price reduction of FFF 
machines and consumables, rapid manufacturing is now more and more often replaced with the term distributed manufacturing, implying the shift from making exclusive products to massive production of commodities [32-38]. Laying aside Fused Granular Fabrication (FGF) machines, operating on polymer pellets or regrind, as described by Woern et al. [39] and Reich et al. [40] showing the performance increased by $1200 \%$ as compared with a baseline of contemporary desktop 3D printer, the following tendency can be formulated. While the performance of machines printing with molten polymers has only increased a few times since their appearance, the average price of such a machine fell by several orders of magnitude. The relatively low performance of desktop 3D printers is compensated by their affordability and thus their broad distribution. Thus, the key advantage of the technology is flexibility rather than productivity.

One of the most important factors for the success of the new manufacturing paradigm is the ability to ensure predictable quality when creating functional products. Thus, increasing the mechanical properties of the 3D printed products obtained with the FFF technology became an area of research and engineering of high interest. There are many approaches designed, many of them requiring hardware modifications in the 3D printers with FFF technology. Thus, Shih et al. [41] suggest low-temperature plasma to activate the sublayer, obtaining samples of double strength compared with reference. Go \& Hart [42] proposed to preheat the filament with the laser, and Ravi et al. [43] used the laser to preheat the sublayer. Kishore et al. [44] heated the sublayer with infrared source. In experiment, performed by Lederle et al. [45] 3D printing is performed in the controlled atmosphere with oxygen excluded, resulting in a $38.6 \%$ increase in tensile strength for nylon samples (with relatively high standard deviation within the test group) and only $6.2 \%$ for ABS. There are also approaches introducing certain pre- or postprocessing applied to the raw material or to the printed part. For example, Abourayana et al. [46] utilized plasma treating for activation of pellets before the filament extrusion, thus increasing the tensile strength of the prints by $22 \%$ at the cost of multi-stage gas treatment process. Shaffer et al. [47] studied the influence of ionizing radiation on printed sample strength. A microwave heating is used for strengthening of printed parts in the research by Sweeney et al. [48], and ultrasonic vibrations are utilized for the same purpose by Li et al. [49], and by Tofangchi et al. [50]. Thermal annealing is applied to printed parts by Hart et al. [51] and Singh et al. [52]. There are recent studies of effects of new materials being included into FFF process, such as PC [53] or PEEK [54,55], as well as composites with discrete [56] and continuous fiber infill [57] suggested by Lu et al, graphene [58] by Caminero et $\mathrm{al}$, and special additivities described by Levenhagen et al $[59,60]$. However, the potential to increase the strength of the samples printed with the most popular material, the Poly (Lactic Acid) or PLA, is not fully revealed. This increase in strength is possible by tuning printing process on a common desktop 3D printing machine.

It was shown in our previous work [61] that layer cohesion increases along with $\mathrm{N} / \mathrm{l}$ value increase- the ratio of the diameter of the nozzle with which printing is performed to the layer thickness. It was also shown in another work [62] by our research team that temperature conditions at the point where a new layer is deposited also have a great influence on the formation of a durable product, as well as extrusion efficiency. Temperature conditions at the site of bond formation can be expressed through the sublayer temperature parameter. This is the temperature of the previous layer print, depending on the extrusion temperature, cooling conditions, and layer printing time (the latter, in turn, is determined by the print speed and part shape) at the moment when the same position in the new layer is extruded. Extrusion efficiency is defined as the ratio of the actual part mass to the calculated from models. The extrusion efficiency seems to be very dependent on hardware [63], but within single hardware configuration, it also depends on the melted polymer viscosity (which in turn depends on extrusion temperature) and the flow rate.

The current study is the continuation of a recent study [64], which demonstrated the importance of part shape design with respect to FFF technology peculiarities and its influence on the sample strength. There were five different $\mathrm{CAD}$ models of an axisymmetric part with constant coupling dimensions converted into PLA FFF parts and then tested with radial loading (Figure 1). 


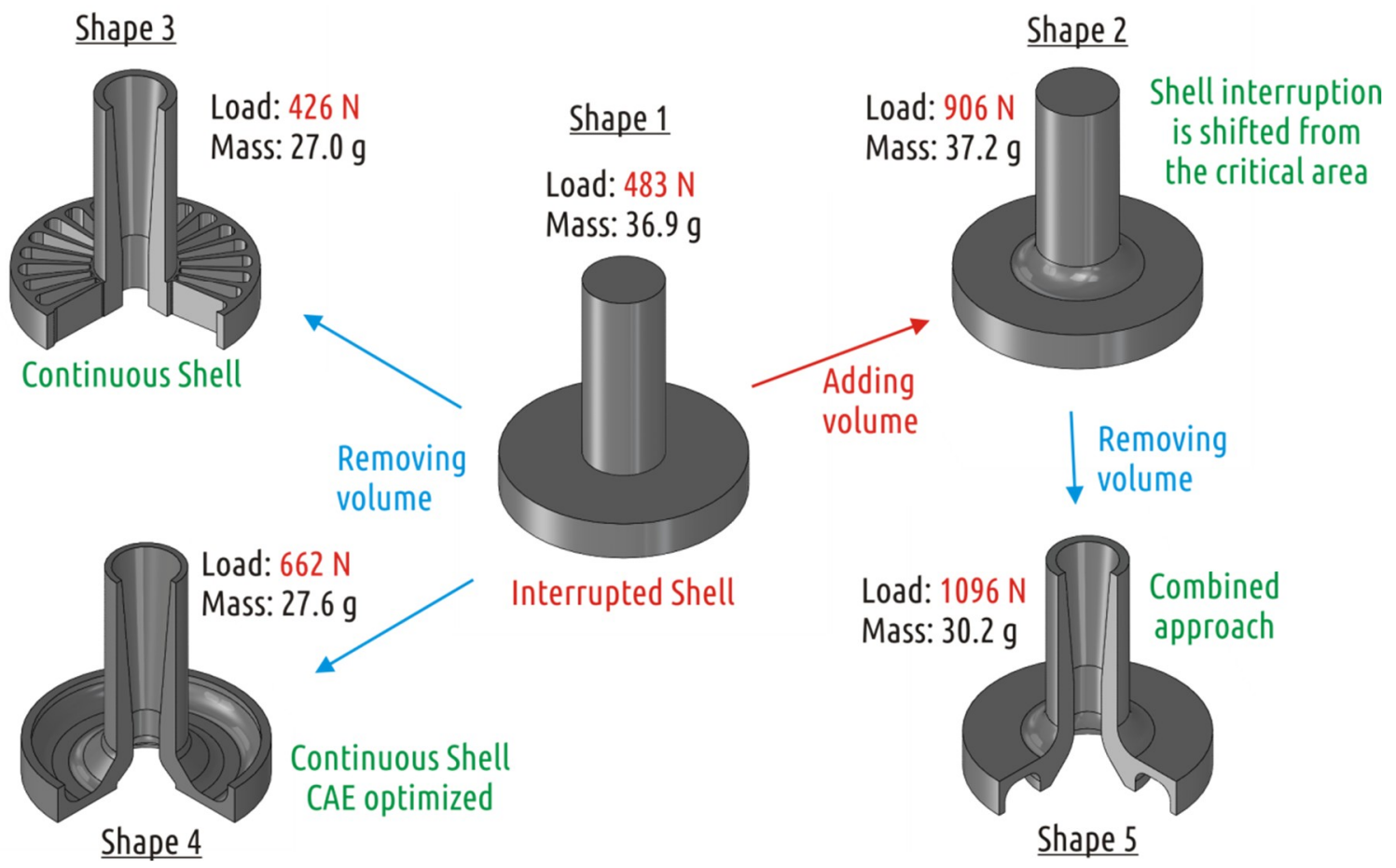

Figure 1. Testing part geometry optimization and results of the study [64].

Shape 1 was used as a representative of common issue of FFF parts when the shell mimicking the part geometry interrupts forming a weak spot (Figure 2). Shapes 2-5 represent different attempts to solve the interrupted shell issue. Shape 2 is based on the traditional approach of increasing strength of weak sections by local addition of material (a fillet between shaft and boss section in this case). Shapes 3 and 4 are attempts to increase the part strength by having in mind specifics of FFF technology. While Shape 3 is formed on intuition, Shape 4 is a result of several iterations of design and simulations. Finally, Shape 5 is a combination of traditional approach (adding a fillet) and based on understanding FFF process design optimization (i.e., removing some CAD model volume to form continuous shell). By applying that combined approach it was possible to increase the part fracture load from $483 \mathrm{~N}$ (Shape 1) to $1096 \mathrm{~N}$ (Shape 5) with some reduction of weight of the part.

In the work [61] it is shown that model design is a keystone for making strong parts, but it lacks any effort to optimize printing parameters. The current paper aims to close that gap and assess the capabilities of different models designed to be printed with the highest possible mechanical properties.

The goal of current research is to establish more general guidelines to increase printed parts strength that would be applicable to FFF printers of different types. The current work shows the effect of tuning the FFF process parameters on the strength of the samples of the same five shapes. The tuning of process parameters is based on findings of previous works [61,62]. Along with "coarse" tuning-altering printing parameters for the whole printing cycle- "fine" tuning is also studied. In the latter case three parameters are varied during the printing cycle depending on the specific part of the sample being printed. It is shown that for a complex part, for an optimized geometry (and only for it), a significant increment of mechanical performance is achievable by optimization of FFF process parameters. 


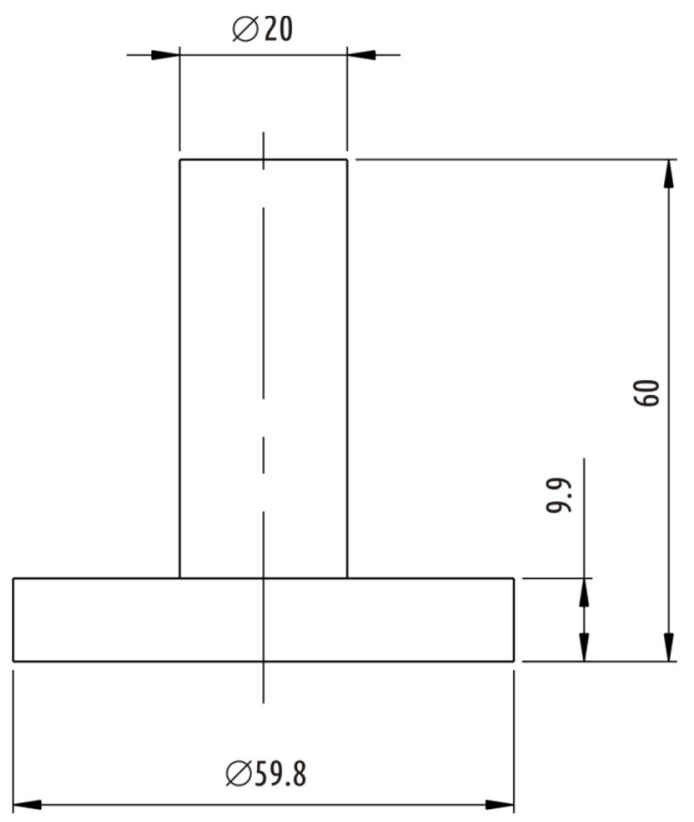

a.

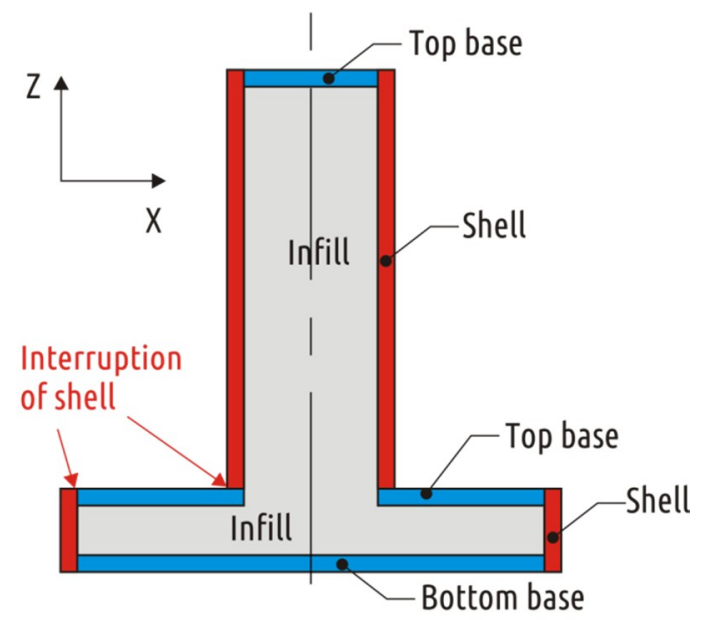

b.

Figure 2. Shape 1 dimensions (unit: $\mathrm{mm}$ ) (a) and constitution (b) with shell interruption highlighted.

\section{Methods and Materials}

\subsection{Sample Shapes}

The shapes of samples tested were inherited from a previous study [64]. An item consisting of two connected coaxial cylinders of large (boss) and small (shaft) diameters was used as basic shape (Shape 1), the dimensions and constitution (superposition of shell, bases, and infill) of the printed part are shown on Figure 2. Four different approaches to increase the strength of such a part by modifying its shape and constitution resulted in four additional shapes (Shapes 2-5), its constitution is shown in Figure 3.

For CAD models with relatively large volume (Shapes 1 and 2), the configuration provided maximum strength in the previous study [64] (base thickness $1.2 \mathrm{~mm}$, shell thickness $2.4 \mathrm{~mm}$, infill $60 \%$ ) was fabricated and tested. For CAD models with lower volume (Shapes 3-5), the same single configuration that was tested in the previous study [64] was used: shell thickness $1.8 \mathrm{~mm}, 100 \%$ infill, and no bases (base thickness $0 \mathrm{~mm}$ ). 


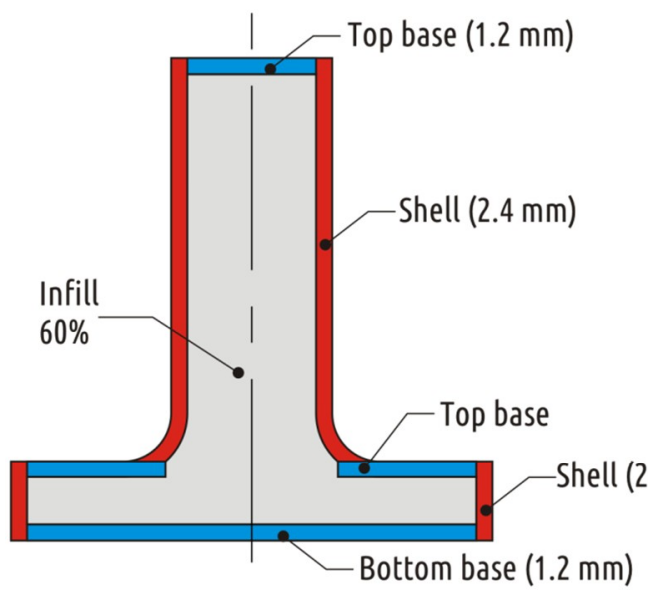

a.

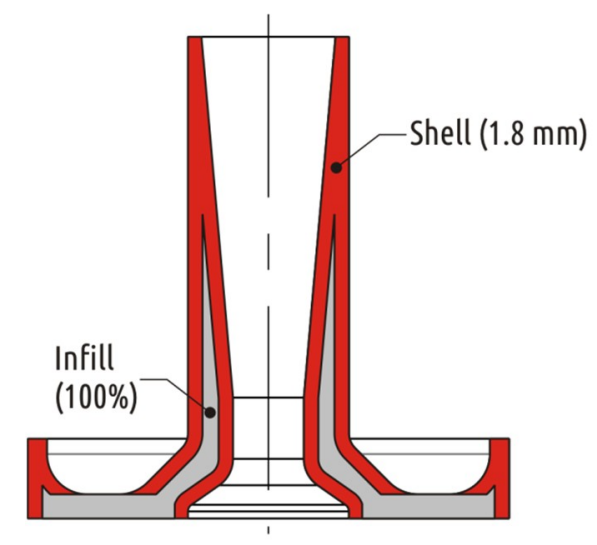

c.

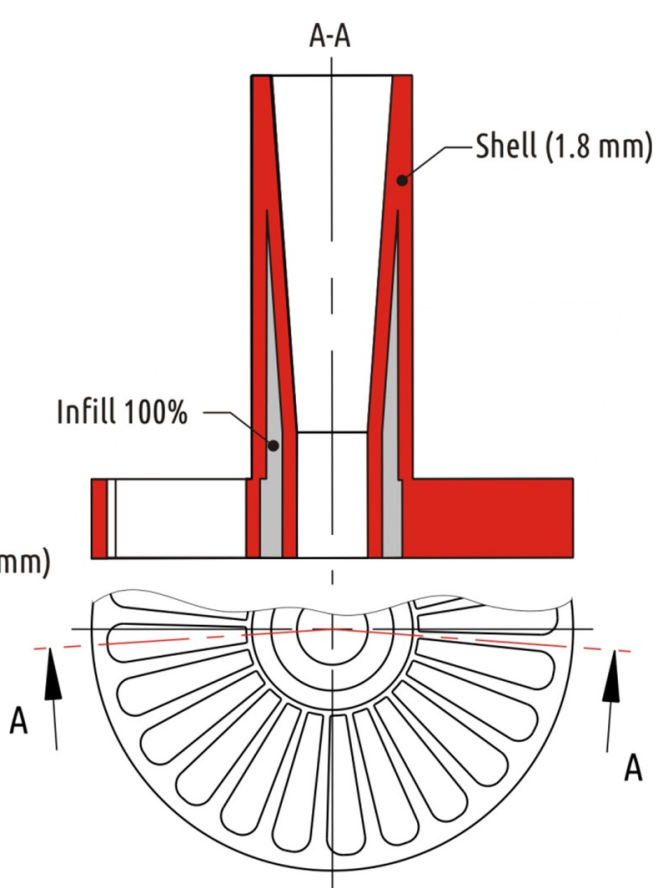

b.

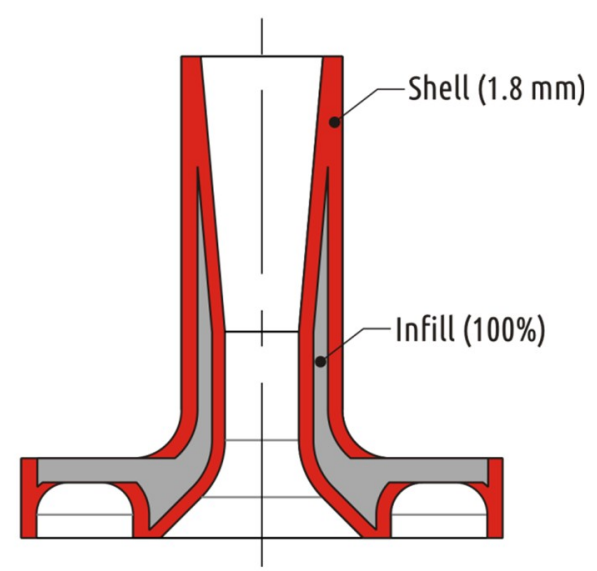

d.

Figure 3. Constitutions of extra shapes, representing different approaches to strengthening the part: Shape 2-traditional approach (a); Shape 3-conversion of interrupted shell into continuous one (b); Shape 4-result of CAD/CAE iterative optimization (c); and Shape 5-combined approach (d).

\subsection{Samples Fabrication}

A desktop Ultimaker 2 printer (Ultimaker B.V., Geldermalsen, The Netherlands) was used to produce all the samples. The specific machine used differs from the mass-market model with an installed alternative feed mechanism of the BondTech brand, built on a stepper motor with an integrated gearbox and drive to both feed rollers, and an alternative 3D Solex (Cepta AS, Oslo, Norway) heating unit with an increased power heating element $(\sim 50 \mathrm{~W})$. The alternative heating unit, unlike the stock one, allows changing nozzles. In this series of experiments, a brass nozzle with a channel diameter of $0.6 \mathrm{~mm}$ was used instead of the $0.4 \mathrm{~mm}$ standard nozzle found in stock Ultimaker 2 printer.

A turquoise PLA filament of $2.85 \mathrm{~mm}$ in diameter was used, produced by REC Company (Moscow, Russia). This specific manufacturer of filament was chosen due to locally produced material and the desire to obtain results comparable with previous studies [61-64]. 
The values of the following printing parameters remained constant during all experiments:

- $\quad$ Nozzle diameter $(0.6 \mathrm{~mm})$

- Heated bed temperature $\left(60^{\circ} \mathrm{C}\right)$

- $\quad$ The first layer thickness $(0.3 \mathrm{~mm})$

- The first layer printing speed $(25 \mathrm{~mm} / \mathrm{s})$

In addition to the technological parameter combination tested in the previous study [64] (Mode A), four extra modes of the printing process were used (Table 1). Modes B-D were used for fabrication of samples of all the shapes considered. Mode E was developed and tested for the single shape (Shape 5), which demonstrated highest strength results in the previous study (printed in mode A). In modes A-D the printing parameters remained unchanged starting from the second layer until the end of fabrication. In E mode, the extrusion temperature, flow rate, and fan speed were changed during the printing process.

Table 1. Printing modes of samples fabrication.

\begin{tabular}{cccccc}
\hline Mode & $\begin{array}{c}\text { Layer } \\
\text { Thickness, } \mathbf{~ m m}\end{array}$ & $\begin{array}{c}\text { Print Speed, } \\
\mathbf{m m} / \mathbf{s}\end{array}$ & $\begin{array}{c}\text { Flow Rate, } \\
\mathbf{m m}^{\mathbf{3}} \mathbf{s}\end{array}$ & $\begin{array}{c}\text { Extrusion } \\
\text { Temperature, }{ }^{\circ} \mathbf{C}\end{array}$ & Fan Speed, \% * \\
\hline A & 0.3 & 30 & 5.4 & 210 & 100 \\
B & 0.3 & 30 & 5.4 & 250 & 0 \\
C & 0.1 & 60 & 3.6 & 210 & 100 \\
D & 0.1 & 60 & 3.6 & 250 & 0 \\
E & 0.3 & 30 & $5.4-7.02$ & $210-250$ & $0-100$ \\
\hline \multicolumn{7}{r}{$0 \%$-the fans are off; $100 \%$-the fans are running at maximum speed. }
\end{tabular}

For each observation mentioned in the work, five samples were made and tested. The paper presents the average values for each test lot, while the standard deviation is indicated after the average value in parentheses. The sample was placed at the center of the printer bed. The G-code file was prepared using Cura 15.02.1 software (slicer) [65]. All samples printed were weighed before mechanical testing using digital analytical scales ViBRA LF Series (Shinko Denshi Co. LTD, Tokyo, Japan). Measurement results were rounded to one decimal digit.

\subsection{Mechanical Testing}

Sample strength tests were carried out on a standard universal electromechanical testing machine IR 5057-50 (OOO Tochpribor, Ivanovo, Russia) with a digital control system. The samples were fixed with a specially designed and manufactured device (Figure 4). That fixture was mounted on a movable traverse of the testing machine. The top roller from the three-point bend test kit was used to apply radial load on the sample shaft. 

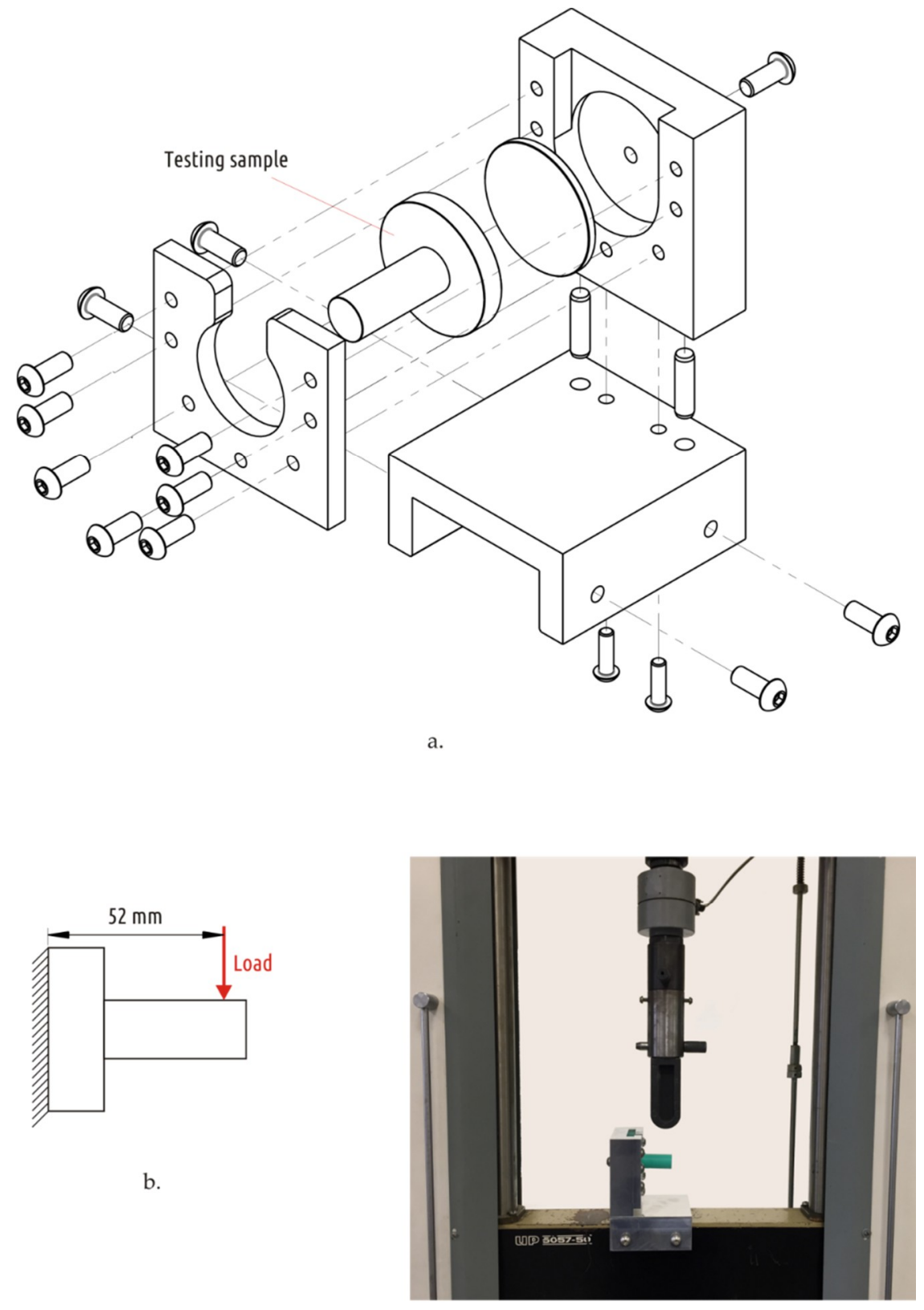

c.

Figure 4. Sample fixture assembly (a), loading scheme (b), and overall view of testing apparatus (c).

The tests were carried out at constant speed $(10 \mathrm{~mm} / \mathrm{min})$ and continued until the sample was destroyed. During the tests displacements and loads were recorded. The reference point was the state of the machine with a load of $5 \mathrm{~N}$ applied to eliminate mounting clearances. The part strength was assumed to be equal to the load at which the first apparent crack appears. That point can be easily identified on the load-displacement curve. Along with absolute strength, relative strength (fracture load related to the sample mass) was also considered.

\subsection{Sublayer Temperature Evaluation}

During the printing process, the temperature distribution over the surface of some samples was recorded using a FLIR B335 (FLIR Systems, Wilsonville, OR, USA) thermal imager with a resolution of $320 \times 240$ pixels. The camera was located in front of the printer at a distance of about $30 \mathrm{~cm}$, which is equal to minimal focal distance documented for the imager. The software "FLIR Tools" [66] was 
used to determine the average temperature on the sample surface at a distance of approximately 1 to $3 \mathrm{~mm}$ from the lower cut of the nozzle (see Figure 5), this temperature was taken as the sublayer temperature $\left(\mathrm{t}_{\mathrm{SUB}}\right)$.

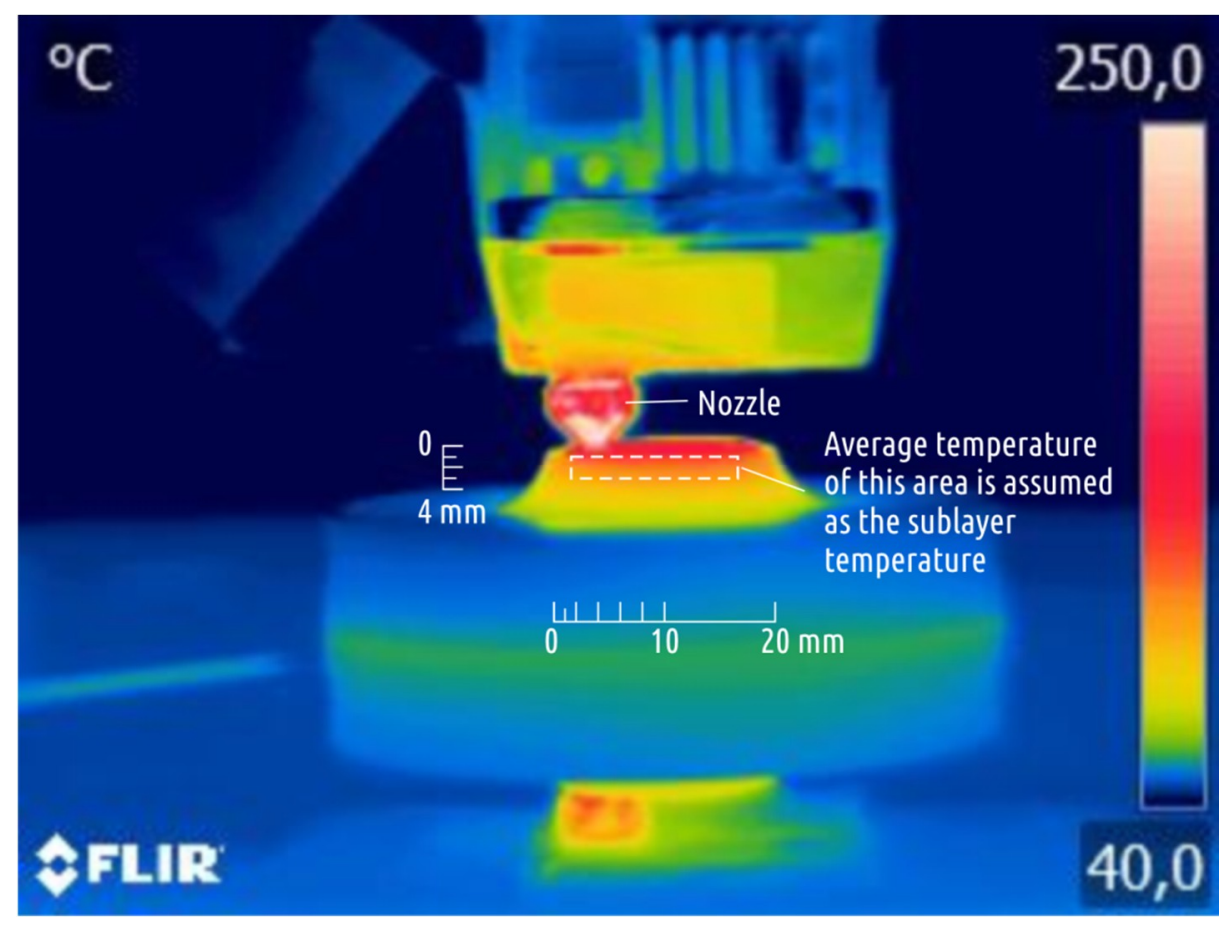

Figure 5. Sublayer temperature evaluation.

\subsection{Macrostructure Evaluation of Fracture Surfaces}

Images of fracture surfaces of tested samples were taken with a Sony A6000 (Sony Corp., Tokyo, Japan) digital camera, equipped with Sony E $35 \mathrm{~mm}$ f1.8 lens and four macro rings with overall length of $52 \mathrm{~mm}$. Images were taken with $\mathrm{f} / 18$ aperture, 3 to $5 \mathrm{sec}$ exposure and ISO 100 sensitivity. For areas with deep relief several images with different focuses were taken and then combined with Enfuse 4.2 software [67]. Displaying the images on high definition computer monitor achieved approximately $100 \times$ magnification. The resulting images contained from 24.7 to 28 million pixels.

\section{Results and Discussion}

\subsection{Technological Parameters Coarse Optimization}

The Table 2 shows the results obtained for all shapes tested in A-D printing modes. Data on A mode has already been published in recent study [64].

The results obtained for the Shape 1 samples are different from all the others: the proven recipes for increasing the interlayer bonding strength (tested when printing samples consisting of continuous shells) are completely inefficient for the interrupted shell case. All Shape 1 specimens tested were fractured at the boundary between the shaft and the base, same as in the previous study [64].

For Shapes 2-5, all optimized modes (B-D) tested showed significant increase in the part strength relative to the baseline (mode $A$ ). The maximum strength was recorded for parts printed in mode $D$, then modes $B$ and $C$, in descending order. The sample mass changes were organized in descending order: D, B, C, and finally A.

Samples for Shapes 2, 4, and 5 printed in modes B-D were destroyed at greater load but at the same area as in the previous study [64] (corresponding to mode A). At the same time, qualitative differences occurred for Shape 3 samples destruction behavior (Figure 6). 
Table 2. Experimental data. The first value is the average and the value in parentheses denotes standard deviation.

\begin{tabular}{|c|c|c|c|c|c|}
\hline Shape & Mode & Printing Time, hh:mm & Mass, $\mathrm{g}$ & Strength, $\mathbf{N}$ & Relative Strength, N/g \\
\hline \multirow{4}{*}{1} & A & $1: 59$ & $36.9(0.2)$ & $483(47)$ & 13.1 \\
\hline & $\mathrm{B}$ & 2:01 & $37.5(0.2)$ & $420(36)$ & 11.2 \\
\hline & $\mathrm{C}$ & $3: 13$ & $37.0(0.2)$ & $433(32)$ & 11.7 \\
\hline & $\mathrm{D}$ & $3: 14$ & $37.6(0.2)$ & $412(28)$ & 10.9 \\
\hline \multirow{4}{*}{2} & A & 2:01 & $37.2(0.2)$ & $906(52)$ & 24.4 \\
\hline & $\mathrm{B}$ & 2:02 & $38.6(0.2)$ & $1382(85)$ & 35.8 \\
\hline & $\mathrm{C}$ & $3: 23$ & $37.6(0.1)$ & $1280(64)$ & 34.0 \\
\hline & $\mathrm{D}$ & $3: 24$ & $39.1(0.2)$ & $1420(34)$ & 36.3 \\
\hline \multirow{4}{*}{3} & $\mathrm{~A}$ & $1: 48$ & $27.0(0.1)$ & $427(26)$ & 15.8 \\
\hline & B & $1: 49$ & $28.0(0.1)$ & $701(55)$ & 25.0 \\
\hline & $\mathrm{C}$ & $3: 34$ & $27.7(0.1)$ & $620(72)$ & 22.4 \\
\hline & $\mathrm{D}$ & $3: 36$ & $28.5(0.1)$ & $787(44)$ & 27.6 \\
\hline \multirow{4}{*}{4} & $\mathrm{~A}$ & $1: 37$ & $27.6(0.1)$ & $662(51)$ & 24.0 \\
\hline & B & $1: 39$ & $28.7(0.1)$ & $875(54)$ & 30.5 \\
\hline & $\mathrm{C}$ & $2: 57$ & $28.3(0.1)$ & 758 (21) & 26.8 \\
\hline & $\mathrm{D}$ & $2: 58$ & $29.1(0.1)$ & $923(30)$ & 31.7 \\
\hline \multirow{4}{*}{5} & A & $1: 46$ & $30.3(0.2)$ & $1026(72)$ & 33.9 \\
\hline & B & $1: 47$ & $30.9(0.1)$ & $1596(32)$ & 51.7 \\
\hline & $\mathrm{C}$ & 3:18 & $30.8(0.1)$ & $1343(46)$ & 43.6 \\
\hline & $\mathrm{D}$ & $3: 18$ & $31.6(0.2)$ & 1695 (68) & 53.6 \\
\hline
\end{tabular}

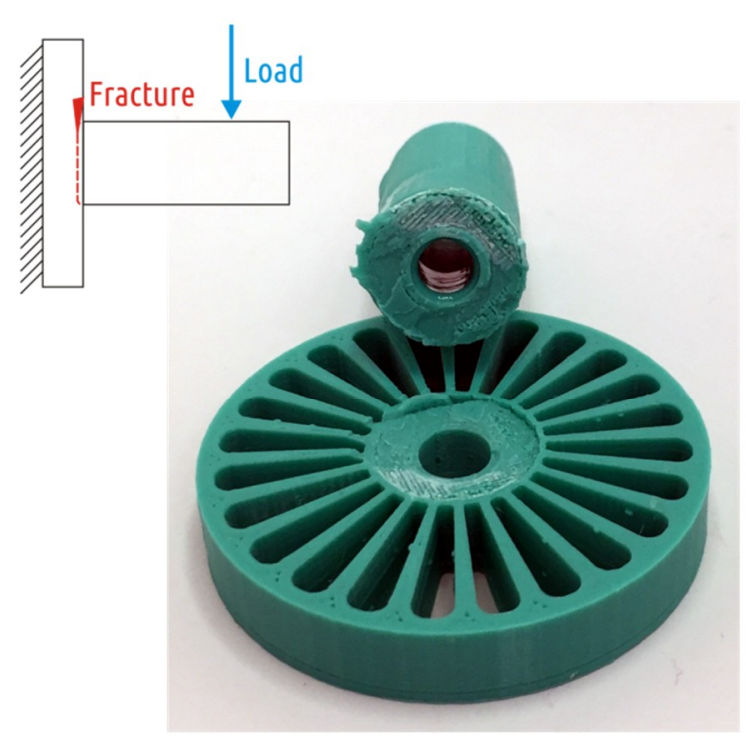

a.

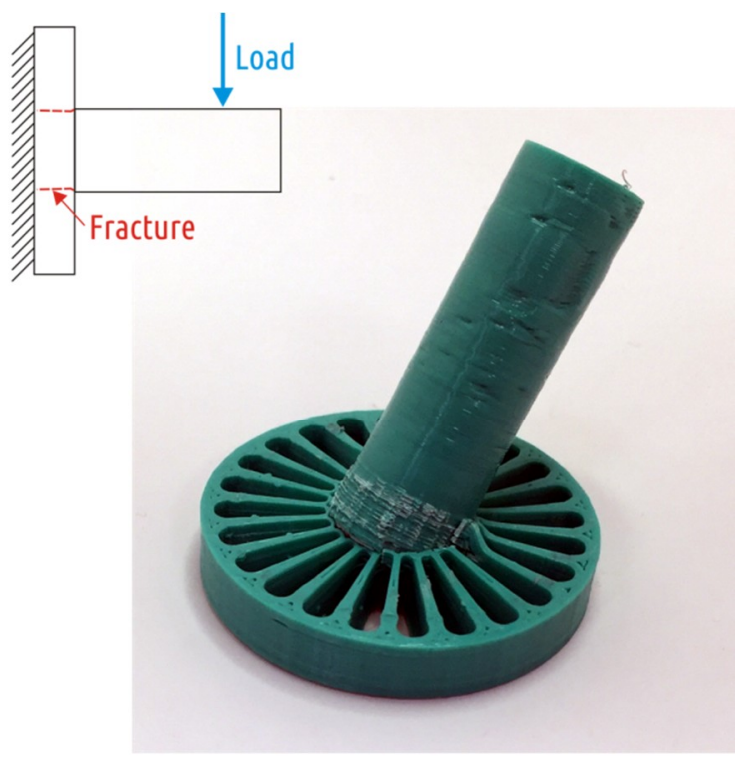

b.

Figure 6. Destruction of Shape 3 samples printed in mode A [64] (a) and mode B (b). For the mode B sample, after the test is over, it is still not possible to separate the shaft from the boss with bare hands.

In samples printed on the modes A and C, the fracture occurred along the shaft section (Figure 6a). In samples printed in modes B and D the shaft remained solid and was pulled out from the boss (Figure 6b). In the second case, even after the cracks appeared and the shaft deviated from the original axis by up to $30^{\circ}$, the part did not break up into fragments.

For all shapes printed in mode $C$, not only did the strength increase, but also an improvement in the visual surface quality (the resolution along the $\mathrm{Z}$ axis increases 3-fold) compared with the baseline (mode A), since surface roughness decreased together with layer thickness, and no distortions occurred. 
Modes featuring increased temperature and fans switched off (modes B and D), on the contrary, lead to distortions of the shape and defects on sample surface. The latter can be examined on the Shape 5 samples, the only model featuring horizontal overhanging elements. Printing such overhanging sections with no support is possible due to the "bridging" effect. Like a bridge span, portion of a certain layer is supported only by side pillars; in the case of Shape 5, these are outer rim and the central hub of the boss (see Figure 3d). The molten plastic threads stretch between the structures already printed as the nozzle moves between them. Sagging curvature depends on filament thread thickness, span length and plastic viscosity (extrusion temperature and cooling conditions). Increased extrusion temperature and disabled fans adversely affect the ability of the printer to make "bridges". Figure 7 shows samples of Shape 5 below.

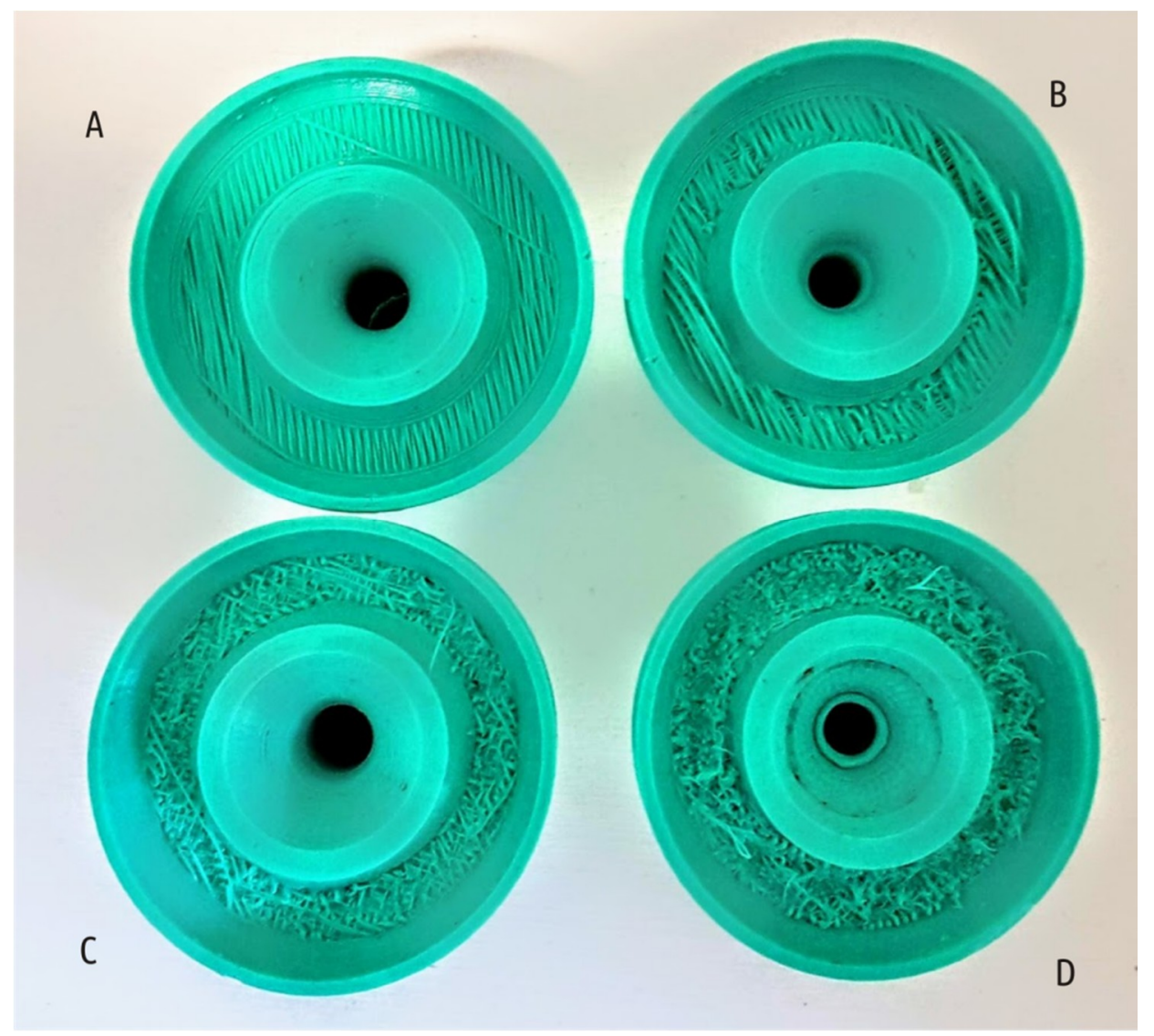

Figure 7. Shape 5 samples, bottom view: overhanging part of the boss when printing in the modes $\mathrm{A}$, B, C, and D, as labeled.

In addition to sagging of unsupported areas, the "hot" settings (modes B and D) caused defects on the side surface of the shaft (Figure 8).

These defects signify the overheating of the part during printing. The temperature of the upper printed layers depends not only on the extrusion temperature and cooling conditions, but also on the previous layers printing time. The latter, in turn, depends on the feed rate and the part shape. The upper layers temperature was recorded when printing in A-D modes (Figure 9) with the aid of infrared thermal visor. 


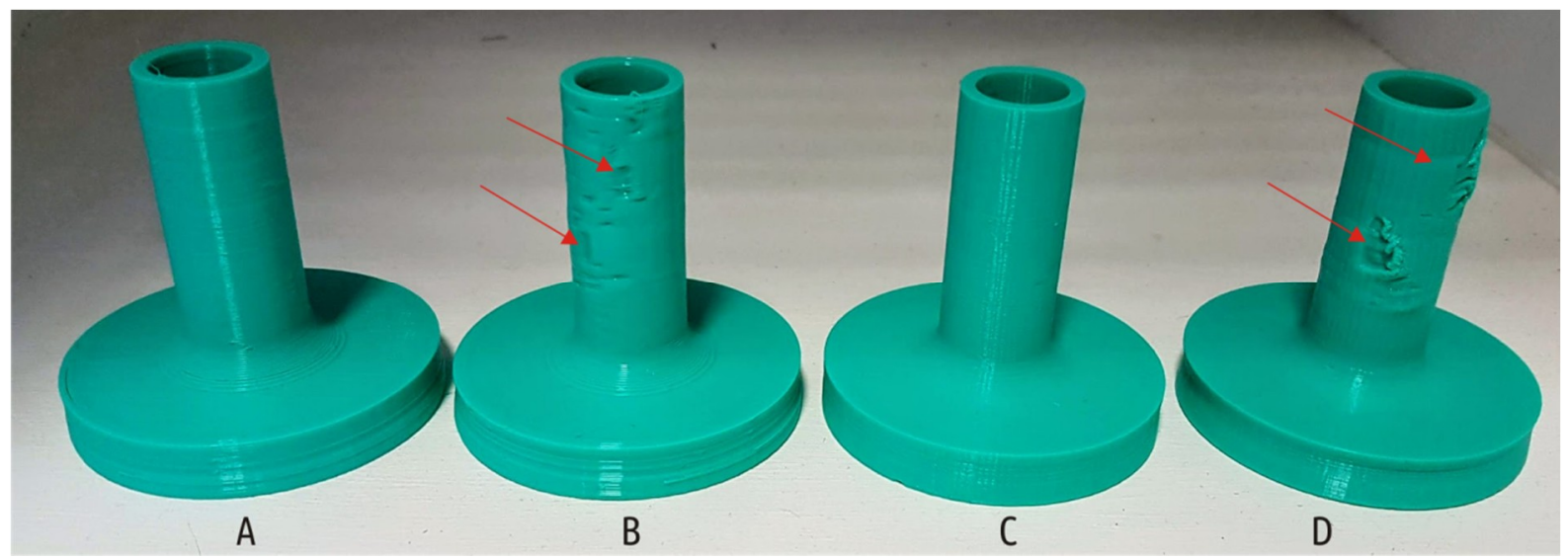

Figure 8. The appearance of the Shape 5 samples printed on the modes A, B, C, and D; red arrows indicate serious defects.

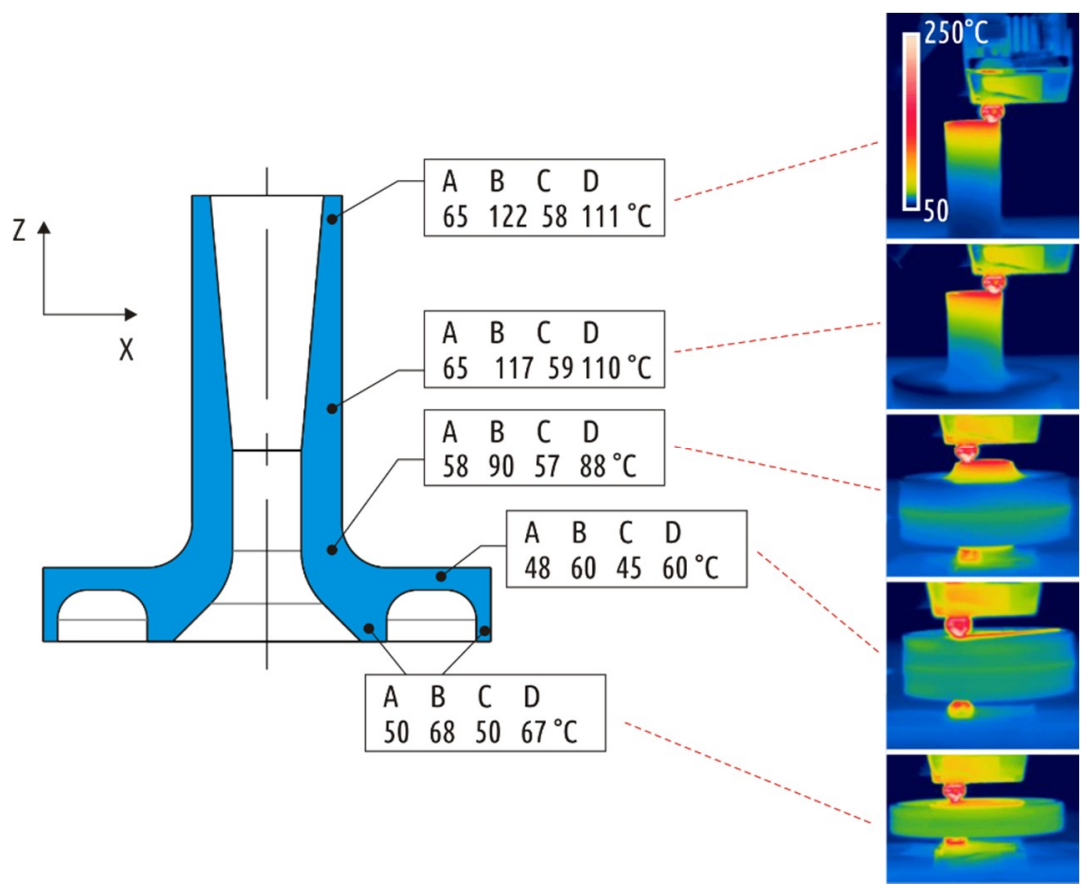

Figure 9. Sublayer temperature recorded at different stages of printing Shape 5 samples in modes A, B, $\mathrm{C}$, and D (thermogram examples are given for mode B).

The highest temperatures were recorded when printing in mode B. When layers with large cross section (boss) have been being printed, the temperature remained at $60^{\circ} \mathrm{C}$, but as cross-section area decreased (shaft), the temperature gradually rose to 90,117 , and $122^{\circ} \mathrm{C}$. At temperatures exceeding the glass transition temperature $\left(70^{\circ} \mathrm{C}\right.$ for PLA), the plastic remains pliable and easily deformed resulting in defects being formed (Figure 8). The slicer used in this study does not add a command to retract the filament at the moment of layer change, thus a small portion of excessive plastic is oozing and being added to the part while the table is moving down before the next layer is started. The build plate of the Ultimaker 2 is not rigid and is rested on three springs. If a nozzle collides with a minor flush on the sublayer, it is normally compensated by lowering of the build plate (with the springs being compressed underneath the plate). In case the sublayer becomes hot and thus soft, the nozzle just smashes a portion of already deposited plastic out of its way instead of pushing the part with the build plate down. These defects become especially noticeable when printing in mode D. Comparing modes 
B and D, mode B features slightly higher temperature of the upper layers, but for mode D, due to thinner layers, the hot nozzle moves much closer to the previous layer.

Thus, any of the options considered for increasing the part strength by modifying the technological modes is a compromise. Decreasing the layer thickness leads to longer printing time, and increase in the sublayer temperature leads to the defects appearance on the surface. However, the negative consequences of such modification of print modes can be minimized. Printing with thinner layers (with relatively low flow rate) can be carried out at higher speeds, thus minimizing time loss. Overheating of parts can also be avoided if the fan blow rate is controlled depending on current layer area instead of simply disabling it.

\subsection{Technological Parameters Fine Tuning}

Part geometry optimization to increase its strength can be summarized, in general, to redistribution of material from less to more loaded areas. In the case of FFF technology, additional material can be supplied to the most critical elements of the part being printed without changing the CAD model. FFF is a technology where material is added layer by layer; thus, it is possible to add the material in larger or smaller quantities in different regions of the part. Material amount can be controlled through the flow rate parameter, available both in the slicer and through the printer menu.

The default flow rate value, shown as $100 \%$ in printer menu, is calculated by the slicer using the formula

$$
\text { Flow }=N \times l \times F_{r},
$$

where Flow is the flow rate (volumetric printing speed), $\mathrm{mm}^{3} / \mathrm{s} ; \mathrm{N}$ is the diameter of the nozzle channel, $\mathrm{mm} ; 1$ is the layer thickness, $\mathrm{mm}$; and Fr is the feed rate (linear printing speed), $\mathrm{mm} / \mathrm{s}$.

The actual volume of material squeezed out by the correctly set up printer with a Bowden extruder (e.g., Ultimaker 2) through the nozzle per unit of time is always less than the calculated one: the slicer does not take into account the extrusion resistance [63]. As shown in previous study [62], even printing with plastic overheated to $250{ }^{\circ} \mathrm{C}$ at low speed $\left(2.2 \mathrm{~mm}^{3} / \mathrm{s}\right)$ resulted in extrusion efficiency equal to 0.96 only. It seems that the only way to have extrusion efficiency equal to 1 or over 1 is to set the flow rate parameter above $100 \%$. The Figure 10 shows the summary of a short experiment in extrusion efficiency test for the Ultimaker $23 \mathrm{D}$ printer. It used cylindrical specimens $(\mathrm{D}=20 \mathrm{~mm}, \mathrm{~h}=15 \mathrm{~mm})$ printed in accordance with the settings of mode A and constituting of $1.8 \mathrm{~mm}$ shell and $100 \%$ infill with a flow rate from 100 to $130 \%$. The calculated mass is $6.02 \mathrm{~g}$, and the actual mass and diameter of the samples are given in the Table 3.

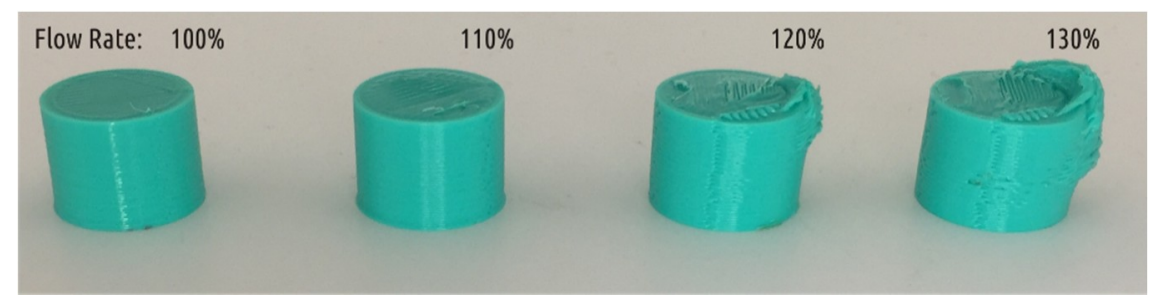

Figure 10. Cylindrical samples 3D printed with different flow rate settings, as labeled.

Table 3. Short experiment on forced overflow data.

\begin{tabular}{cccc}
\hline Flow Rate, $\%$ & Actual Mass, $\mathbf{g}$ & Extrusion Efficiency & Actual Diameter, $\mathbf{m m}$ \\
\hline 100 & $5.61(0.1)$ & 0.93 & $19.7(0.1)$ \\
110 & $5.91(0.1)$ & 0.98 & $20.2(0.1)$ \\
120 & $6.37(0.1)$ & 1.06 & $20.6(0.1)^{*}$ \\
130 & $6.87(0.2)$ & 1.14 & $20.7(0.1)^{*}$ \\
\hline
\end{tabular}

* Excluding flush. 
As it can be seen from the Table 3, an increase in flow rate of $10 \%$ still does not give an extrusion efficiency of 1 (measured by sample mass), but the resulting sample exceeds the diameter designed. An increase in Flow rate of 20 and 30\% leads to significant distortion in shape, namely, to the appearance of a characteristic flush. The excessive plastic location is explained by asymmetrical cooling conditions typical for the Ultimaker printers-the nozzle is blown with two fans, while the left fan is about $30 \mathrm{~mm}$ closer to the nozzle than the right one. The part cools worse on the right side, shape loss occurs there. It should be noted that probably no 3D printer provides ideally uniform cooling.

In addition to the threat of defects appearance and deviation from nominal sizes, the increased flow (increased extrusion efficiency) can significantly increase the cohesion strength between the layers. In addition to the obvious increase in the contact area between the layers, the higher plastic flow leads to increased substrate temperature and pressure towards the sublayer. The maximum effect on particular part strength can be achieved by controlling the value of flow rate during the printing process. Along with this parameter, the other ones can be adjusted separately for different layers, for example, extrusion temperature and cooling conditions.

An optimized printing script (mode E) was prepared for Shape 5 model, described in the Table 4 . Parameter changes were made in the slicer using the Tweak At Z 4.0.1 plugin [68] for the Cura slicer. The same result can be achieved by manually editing the G-code or even by manually operating the printer during the printing process.

Table 4. Fine tuning of the Fused Filament Fabrication (FFF) process (mode E).

\begin{tabular}{ccccc}
\hline Layer \# & $\mathbf{t}_{\mathrm{E}},{ }^{\circ} \mathbf{C}$ & Fan Speed, $\%$ & Flow rate, $\%$ & Comment \\
\hline $1-6$ & 210 & 0 & 100 & Initial printing on the hot plate \\
$6-21$ & 210 & 30 & 100 & Printing the unstressed part of the boss \\
$22-23$ & 210 & 100 & 100 & "Bridging" \\
$24-31$ & 250 & 0 & 105 & Printing the stressed part of the boss \\
32 & 250 & 0 & 115 & Top of the boss part \\
$33-49$ & 250 & 0 & 130 & Printing the critical zone \\
$50-69$ & 250 & 14 & 130 & Printing the critical zone, providing some \\
$70-99$ & 250 & 14 & 120 & cooling to avoid defects formation \\
$100-129$ & 250 & 24 & 110 & Leaving the critical zone \\
$130-200$ & 250 & 24 & 100 & Printing non critical part of the shaft \\
\hline
\end{tabular}

Printing begins at standard extrusion temperature $\left(210^{\circ} \mathrm{C}\right)$ and continues until the overhanging part of the boss has finished printing. At the same time cooling intensity varies from 0 (printing the first layer when it is necessary to achieve high adhesion to the printer bed) to $100 \%$ (when the "bridge" is printed). This slice of the sample experiences relatively small loads; geometrical accuracy here is more important than strength. After the "flooring" of the overhanging part of the boss is complete, extrusion temperature is set to $250{ }^{\circ} \mathrm{C}$, the fans are disabled, and flow rate is increased by $5 \%$. In this way the loaded part of the boss is printed. The top layer of the boss is printed with even higher flow rate value $(115 \%)$, thus forming dense foundation for the shaft. The shaft base is printed with the flow rate increased to $130 \%$ forming the critical area. To avoid substrate overheating and correlated defects, even before the critical zone is finished printing, the fans are turned on at the speed of $14 \%$ of the maximum. After printing the critical area of the part, the fans are accelerated to $24 \%$, and flow rate is reduced to $100 \%$ in three stages. The samples obtained are thus without visible serious defects on the surface and have average mass of $34.2(0.2) \mathrm{g}$. The average strength of the samples obtained under this scenario was $2139(55) \mathrm{N}$. The average relative strength was $62.5 \mathrm{~N} / \mathrm{g}$.

\subsection{Fracture Surface Structure of the Tested Samples}

Analyzing the structure of the surfaces exposed during the samples destruction during the tests allows one to better understand the nature of the processes and grasp the influence of 3D printing modes on the printed part properties. 
Comparison of the fracture surface structure formed during samples testing obtained in different modes using the example of Shape 5 is of particular interest (Figure 11).
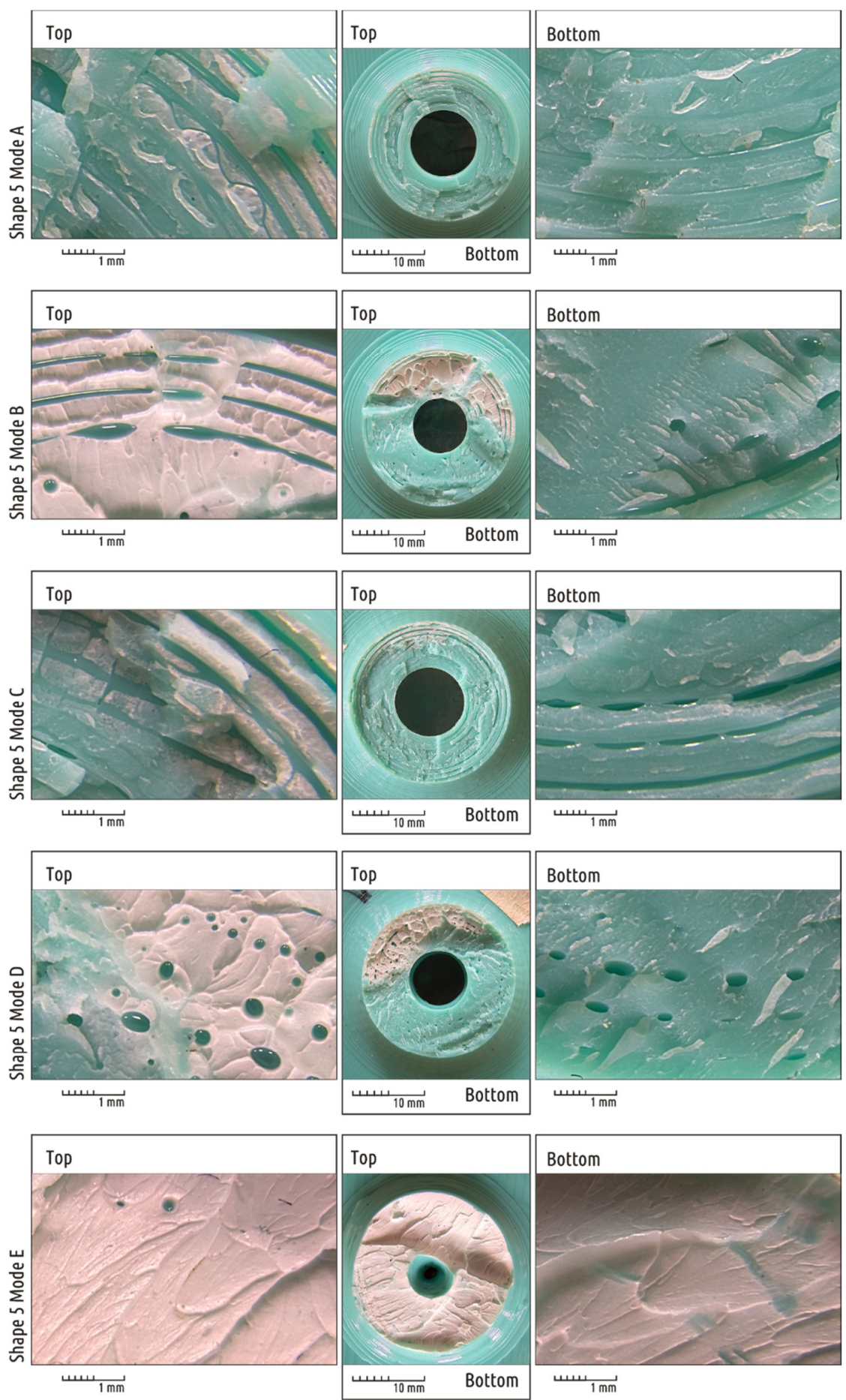

Figure 11. Fracture surface macrostructure of Shape 5 samples manufactured in different modes. "Top" and "Bottom" marks correspond to the position of the specimen at the time of destruction (the load was applied to the "top" surface of the shaft). An image of the entire fracture surface is given in the center for each sample. The fragments from the upper and lower parts are zoomed in to the left and to the right, respectively.

In all cases, the shaft destruction begins from above: the tensile stresses cause a crack to appear that quickly spreads downwards, completing the destruction. In the upper part of the shaft cross-section, 
signs of plastic deformation of the polymer can be observed. They appear in color photographs as whitish areas (Figure 11, top fragments). In the lower part of the cross-section, where fracture occurs by rapid crack growth, signs of plastic deformation are almost absent (Figure 11, bottom fragments). An exception is the cross-section on the specimen obtained in mode E: there are traces of plastic deformation on the entire surface of the fracture. The photos corresponding to different modes display visible quantitative and qualitative differences. There are the contours of the plastic threads forming the part clearly visible on Samples A and C. The samples printed in modes B and D have some fragments of the surface where the boundaries between the threads become indistinguishable.

It is also interesting to analyze the crack surface structure of Shape 4 samples (Figure 12). The destruction is localized in the boss, where plastic threads of the infill predominate. As in the case described above, areas with plastic deformations are clearly readable as faded color of the plastic (white areas). It can be seen that the rupture, which was initially ductile in its nature, is rapidly spreading and destruction changes from ductile to brittle. By analyzing plastic deformations areas it can be concluded that a crack grows in two directions (Figures 12 and 13). The crack spreads over the sample surface, gradually enclosing and dissecting the entire base of the shaft (blue arrows), and also penetrates deep into the part (red arrows).
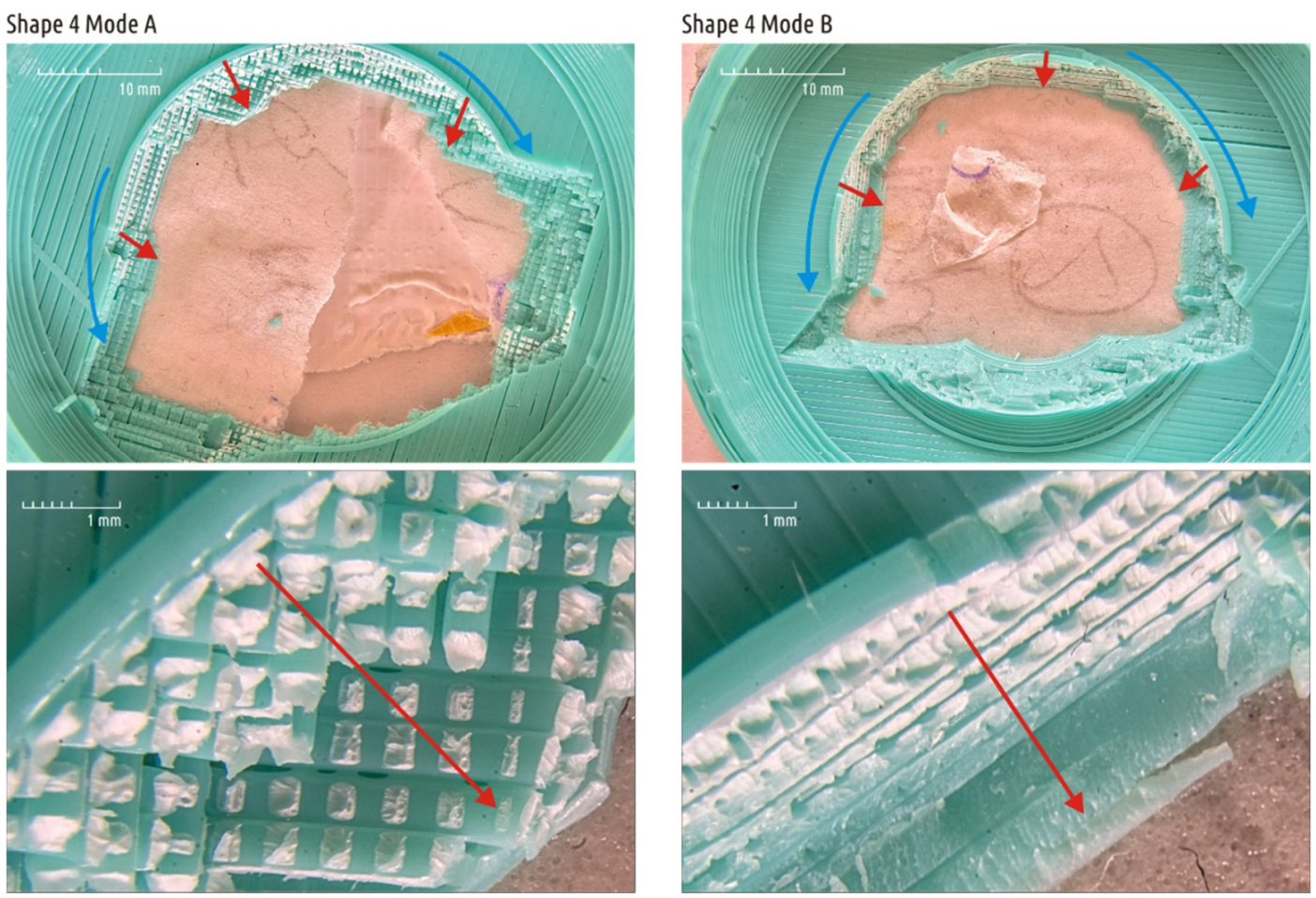

Figure 12. Fracture surface of Shape 4 samples obtained by modes $\mathrm{A}$ and $\mathrm{B}$. The arrows indicate the direction of crack propagation.

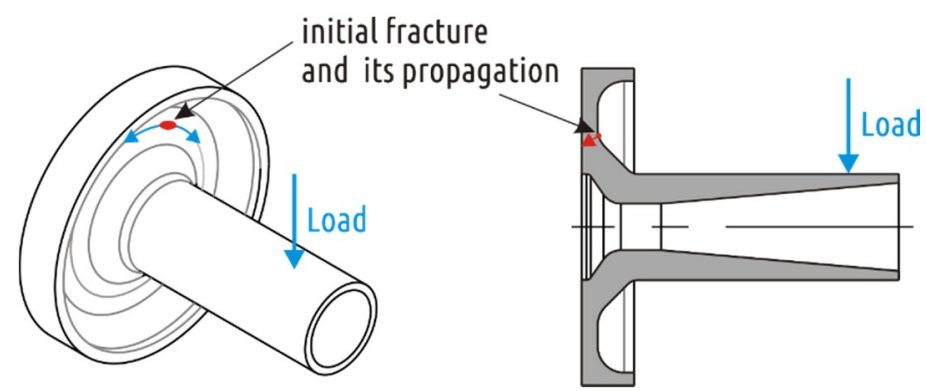

Figure 13. The initial rupture position on Shape 4 samples and the direction of crack propagation. 
The photos clearly show that even with $100 \%$ infill the real contact between the layers is dotted. The orthogonal threads of the adjacent layers have barrel-shaped cross-section and contact their neighbors in limited spots. Unlike the infill, the threads of the adjacent layers forming the shell are deposited parallel to each other. Thus, the layers do not contact in individual spots but in continuous strips (Figure 14). The latter can be clearly seen, for example, on photographs Shape 5 specimen fracture, obtained in modes A-C (see Figure 11).
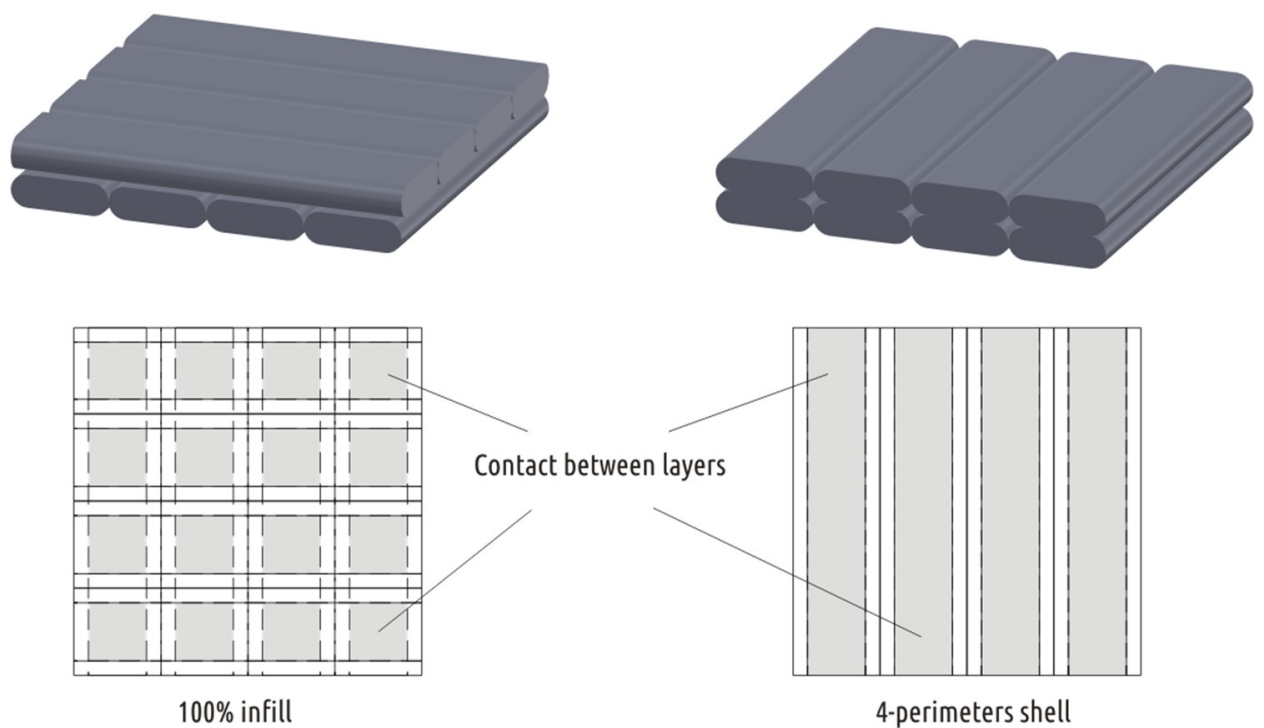

Figure 14. Superposition of polymer threads in adjacent layers of infill (left) and shell (right) and the contact area between the layers.

As the extrusion efficiency increases, the contact spots and stripes become larger. The figure shows that in modes B and D, the voids between individual threads are fragmented and turn into isolated caverns, approaching spherical shape. This effect was noticed and described in detail in previous work [62]. If the part heats up during the printing process and the temperature of the upper layers goes about $110-130^{\circ} \mathrm{C}$, at the moment of new layer deposition the plastic of the sublayer melts. The air filling discontinuities between adjacent threads is surrounded by liquid plastic and the surface tension forces contribute to the gradual transformation of the interface between air and plastic into the regular sphere. It is clearly visible that the air corridors at the boundaries between plastic threads are fragmented and coalesce on the fracture of the Shape 5 sample, printed in mode D.

Finally, under the conditions of overextrusion, i.e., of an excessive plastic supply (mode E), the sample becomes almost solid-the boundaries between the threads become indistinguishable, air pockets are not formed. Any visible difference between the shell and the infill disappears.

\subsection{Comparing Experimental Data with Previously Obtained Models}

Controlling mechanical properties by modifying technological modes requires the result to be predictable. Previous studies derived regression models linking the printing modes (geometric [61] and temperature [62]) and part strength. The dependence of part strength from the $\mathrm{N} / \mathrm{l}$ ratio is described by the formula

$$
\text { Strength }=70.7-\left(\frac{N}{l}\right)^{1.5} \text {. }
$$

Accordingly, the predicted strength values for the modes A (N/1 = 2) and C (N/1 = 6) are 50.1 and 66.7 $\mathrm{MPa}$, respectively. The predicted strengths bonus (the increase in strength for the transition from mode A to mode $\mathrm{C}$ ) is 1.33 . Table 5 shows the relationship of test results obtained for Shapes $2-5$ printed in modes A and C. As it can be seen, the actual values of strength bonuses are quite close to the 
calculated value. Moreover, the average strength improvement for the four different shapes coincides with the predicted value with an accuracy of two decimal places-1.33.

Table 5. Strengthening of parts by lowering the layer height (with transition from mode A to mode C).

\begin{tabular}{cccccc}
\hline Shape & $\mathbf{2}$ & $\mathbf{3}$ & $\mathbf{4}$ & $\mathbf{5}$ & Model \\
\hline Mode A, strength, N & $906(20.1)$ & $427(14.2)$ & $662(18.4)$ & $1026(23.5)$ & - \\
Mode C, strength, N & $1280(22.6)$ & $620(19.3)$ & $758(18.8)$ & $1343(22.2)$ & - \\
Strength bonus & 1.41 & 1.45 & 1.15 & 1.31 & 1.33 \\
\hline
\end{tabular}

The model obtained in the previous study [61] is based on testing samples printed at a constant temperature $\left(210^{\circ} \mathrm{C}\right)$ and a constant feed rate $(25 \mathrm{~mm} / \mathrm{s})$, it does not take into account the influence of thermal factors, and therefore is not applicable to assess the strength improvement, for example, caused by the transition from mode B to mode D. The model obtained in the other study [62], on the contrary, does not take into account geometric factors-it is completely built on samples printed with a single nozzle $(0.6 \mathrm{~mm})$ and layers of the same thickness $(0.3 \mathrm{~mm})$. The adequacy of this model can be assessed by comparing the test results for Shape 5 in modes A and B. The model relates the part strength with the extrusion efficiency value $(\mathrm{E})$ and the sublayer temperature $\left(\mathrm{t}_{\mathrm{SUB}}\right)$ :

$$
\text { Strength }=23.945 \times \ln \left(t_{\text {sub }}\right)+116.58 \times E-153.912 .
$$

For Shape 5 samples, the calculated mass can be evaluated from the total filament length $(4.55 \mathrm{~m})$ consumed to print the product, calculated by the slicer and its density. One meter of the filament used weighs $7.92 \mathrm{~g}$, thus the calculated mass of the Shape 5 sample is $36.0 \mathrm{~g}$. Data on the sublayer temperature when printing the critical part (bottom shaft region) is shown in the Figure 9. Table 6 compares the predicted and observed parameters of the Shape 5 samples for modes A and B.

Table 6. Strengthening of Shape 5 parts by increasing of sublayer temperature and extrusion efficiency (with transition from mode A to mode B).

\begin{tabular}{|c|c|c|}
\hline Parameter & Shape 5, Mode A & Shape 5, Mode B \\
\hline Calculated mass, $\mathrm{g}$ & \multicolumn{2}{|c|}{36.0} \\
\hline Actual mass, $\mathrm{g}$ & $30.3(0.2)$ & $32.3(0.2)$ \\
\hline Extrusion efficiency & 0.84 & 0.90 \\
\hline Sublayer temperature, ${ }^{\circ} \mathrm{C}$ & 58 & 90 \\
\hline Calculated strength, $\mathrm{MPa}$ & $70.9(0.9)$ & $104.2(1.1)$ \\
\hline Actual sample strength, $\mathrm{N}$ & $1026(23.5)$ & $1596(31.2)$ \\
\hline Estimated strength bonus & \multicolumn{2}{|c|}{1.41} \\
\hline Actual strength bonus & \multicolumn{2}{|c|}{1.47} \\
\hline
\end{tabular}

The calculated value of the strength increased caused by the transition from mode A to mode $B$ is close to the actual. It can be stated that currently available models predict quite adequately the efficiency of strength improvement through printing mode optimization, however, these models are not complete. Additional experiments are needed to identify the joint influence of geometric and temperature factors on the part strength for desktop 3D printing technology.

\section{Summary}

The effectiveness of coarse (modes B-D) and fine (mode E) FFF tuning for all tested shapes can be evaluated from Figure 15. Parts of Shape 1, containing critical shell interruption, cannot be strengthened by technological mode optimization as it is shown on the chart (red bars). For all other tested shapes modifying technological modes led to a significant positive effect. Significant increase in strength without loss of product surface and dimensional quality can be achieved by reducing the layer thickness (Shapes 2-5, mode C) or by fine-tuning the 3D printing parameters (Shape 5, mode E). 


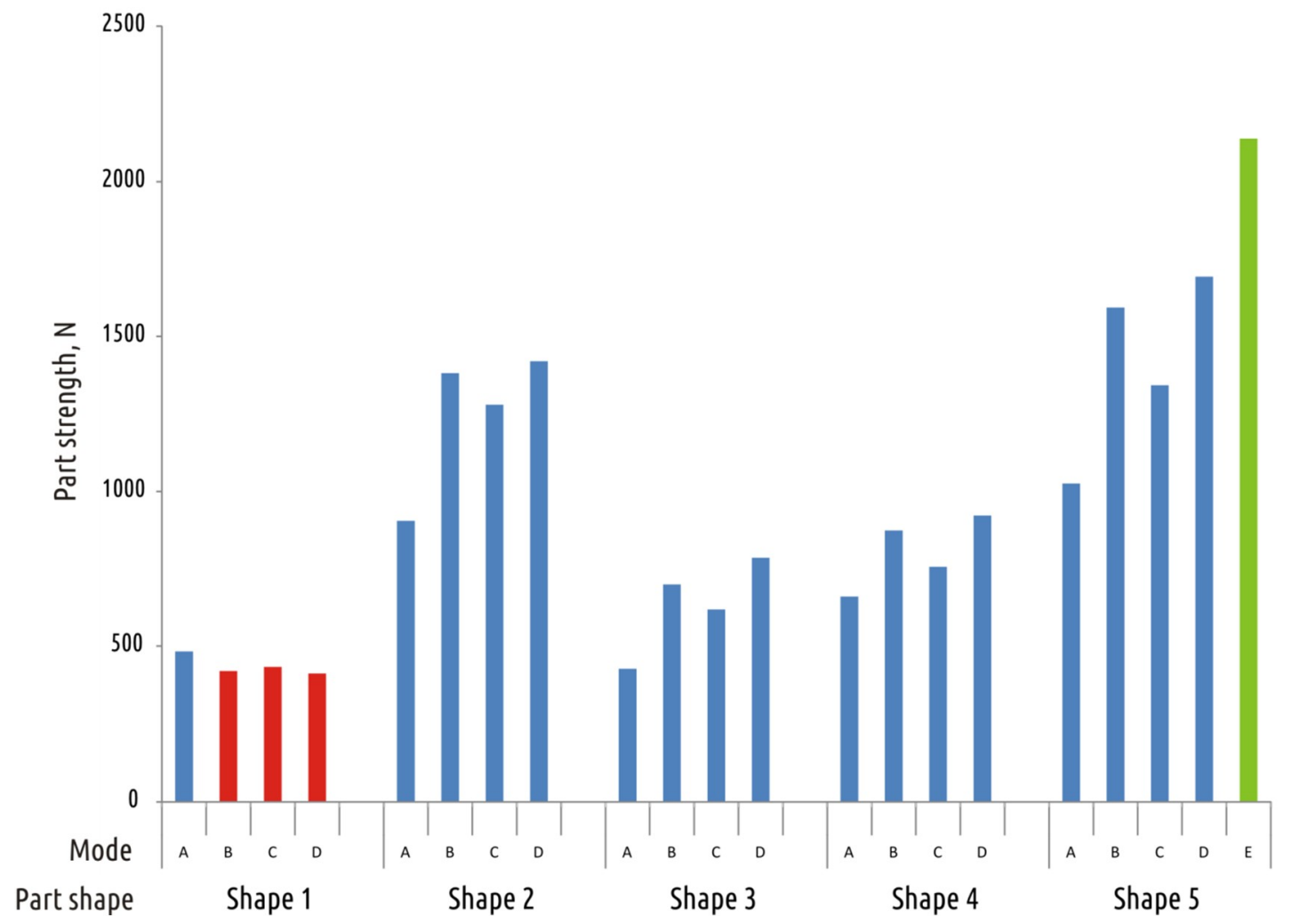

Figure 15. Summary on part strength achieved by different printing modes on all tested shapes.

Comparison of the results obtained for Shape 5 using the A and E printing modes, shows that increasing sample mass by $8 \%$ caused strength improvement by $108 \%$. This impressive result means, however, that in order to achieve best results, the attitude towards the 3D printer should be rethought.

A desktop device operating on the FFF principle should not be viewed as a printer, that is, a tool for visualization (albeit in a tangible format) of computer models. It is rather a production machine with its own advantages and disadvantages, limitations, and capabilities. An ideal printer should have one single button that starts the process of turning a computer file into the printed counterpart. The user does not need to understand and to control the processes inside the black box. On the other hand, if the task is to get not "printouts", i.e., mock-ups (cosmetic prototypes), but solid functional products, a production machine is needed rather than an end-user device. The ideal production machine allows the user to control and adjust all the technological modes. In this case, however, the user must be converted into a technologist, and the technological script for a particular product should be developed. Modern 3D printers are often subdivided into categories of affordable desktop machines (with cost up to USD 2000), much more expensive "professional" machines (with cost from USD 20000 upfront) and even more expensive "production" machines. In this sense, most devices in the category of expensive "professional" 3D printers remain "printers". These machines are limited by a narrow range of proprietary materials and preset parameters values. On the other hand, open source low-end "printers", being an order of magnitude more accessible, give the user full control over the technology. Transitioning from "rapid prototyping" to flexible manufacturing of functional things is possible on the existing hardware base of open source machines, in case product design is taken into account the features of technology and optimization of technological modes is done in accordance with the product shape and purpose.

\section{Conclusions}

To our best knowledge, the current study is the first description of effect of fine tuning the FFF process (the parameters were changed at specific layers) made with part geometry in mind. Fine tuning 
cooling conditions by changing fans rotation speed for different stages within single printing cycle allowed maintaining the sublayer to a temperature of approximately $90{ }^{\circ} \mathrm{C}$, thus providing significant increase in interlayer bonding without causing any visible defects. Fine tuning extrusion temperature (up to $250^{\circ} \mathrm{C}$ ) and flow rate (up to $130 \%$ ) allowed supply of additional material in the most critical section of the part and created an almost uniform and solid mesostructure of the part. Local increase of the flow rate, or controlled overextrusion, may be considered a unique option for the FFF process, not available to other AM technologies and processes without changing the CAD model. The fine tuning of FFF mode resulted in doubled part strength (the mechanical strength in a bending test rose from $1026 \mathrm{~N}$, as achieved by design optimization in the previous study, to $2139 \mathrm{~N}$ ) with negligible increase in sample weight (from 30.3 to $34.2 \mathrm{~g}$ ). Generally speaking, fine-tuning the printing process parameters allows one to minimize negative and maximize positive effects. Meanwhile, technology optimization should be considered as the second step towards the launch of FFF printed product designed to bear loads. The first one remains product design optimization taking into account the features of the FFF technology. The study shows that printing mode optimization does not allow to increase the strength of a sample with a severe design flaw, in the case considered it was the interrupted shell occurring in the critical area (shape 1). Each and every manufacturing technology requires its peculiarities to be considered and process parameters tuned with regards to part shape and purpose. The attitude towards FFF printing process similar to any other production technology allows producing parts with high reliability features and predictable behavior under loads using desktop 3D printers.

Author Contributions: Conceptualization, V.K.; Data curation, A.T.; Investigation, Azamat Tavitov, O.U. and A.K.; Methodology, V.K.; Project administration, V.K.; Resources, S.S. and A.S.; Writing-original draft, V.K.; Writing-review \& editing, V.K., A.T., O.U., A.K., S.S., and A.S.

Funding: This research was funded by the Ministry of Education and Science of the Russian Federation in the framework of increase Competitiveness Program of NUST "MISIS", implemented by a governmental decree dated 16th of March 2013, No. 211.

Acknowledgments: The authors express acknowledgement and deep respect to the paper's reviewers and Benjamin Jacob Valenta for suggestions and edits.

Conflicts of Interest: The authors declare no conflicts of interest.

\section{Nomenclature/Abbreviations}

In the current work, the following notions are introduced and the following shorthand is used.

FFF-Fused Filament Fabrication is a technology of digital additive manufacturing based on material extrusion and layered deposition of melted thermoplastic. From a technological point of view, FFF is the same as FDM®-Fused Deposition Modeling - the only difference is that while the FDM®is a registered trademark and thus applies to Stratasys machines only, FFF is a term coined inside the RepRap community.

Filament-plastic in the filament form used as supply in FFF process.

Thread-extruded and deposited thread of plastic mimicking the FFF part.

Shell-a component of FFF part, reproducing the lateral surface of 3D model. The shell of a layer consists of single or multiple equidistant perimeters formed by the thread. Number of perimeters and the thread wideness are responsible for the shell thickness.

Infill—an internal component of FFF part, formed by threads, usually, in orthogonal straight lines. The distance between the threads describes the infill density.

Base-a component of FFF part, reproducing flat surfaces parallel to the 3D printer bed. Base may consist of multiple layers, usually printed mutually orthogonally in XY directions, and can be disabled.

Fracture load - the load observed during mechanical testing at which the sample exhibits the first crack, in the context of the study, the fracture load is the sample strength. Relative strength - a ratio sample's facture load to its mass.

$t_{E}$ - extrusion temperature - the temperature of the hot end of the 3D printer at which sample is fabricated. Sublayer - a layer of plastic previously deposited by FFF 3D printer that acts as a substrate for layer being deposited at given moment.

$t_{\mathrm{SUB}}$ - temperature of sublayer.

Flow rate $\left(\mathrm{mm}^{3} / \mathrm{s}\right)$ - the volume of plastic delivered through the nozzle per unit time. Flow rate $(\%)$ - parameter available in printer control allowing to force an increase $(>100 \%)$ or decrease $(<100 \%)$ of the amount of molten plastic extruded w.r.t. the rate calculated by the slicer at print preparation stage.

Feed rate-the linear printing speed-the speed of nozzle traveling across XY plane while extruding the plastic.

Extrusion efficiency-a ratio of real to calculated mass of 3D printed object. 


\section{References}

1. Colley, D.P. Instant prototypes. Mech. Eng. 1988, 110, 68.

2. Deitz, D. Stereolithography automates prototyping. Mech. Eng. 1990, 112, 34.

3. Ashley, S. Rapid prototyping systems. Mech. Eng. 1991, 113, 34.

4. Kruth, J.P. Material incress manufacturing by rapid prototyping techniques. CIRP Ann. 1991, 40, $603-614$. [CrossRef]

5. Jacobs, P.F. Rapid Prototyping Manufacturing: Fundamentals of Stereolithography; Society of Manufacturing Engineers: College Station, TX, USA, 1992.

6. Wall, M.B.; Ulrich, K.T.; Flowers, W.C. Evaluating prototyping technologies for product design. Res. Eng. Des. 1992, 3, 163-177. [CrossRef]

7. Ashley, S. Rapid prototyping is coming of age. Mech. Eng. 1995, 117, 62-68.

8. Sachs, E.; Cima, M.; Cornie, J. Three-Dimensional Printing: Rapid Tooling and Prototypes Directly from a CAD Model. CIRP Ann. 1990, 39, 201-204. [CrossRef]

9. Dickens, P.M.; Stangroom, R.; Greul, M.; Holmer, B.; Hon, K.K.B.; Hovtun, R.; Neumann, R.; Noeken, S.; Wimpenny, D. Conversion of RP models to investment castings. Rapid Prototyp. J. 1995, 1, 4-11. [CrossRef]

10. Karapatis, N.P.; Van Griethuysen, J.-P.S.; Glardon, R. Direct rapid tooling: A review of current research. Rapid Prototyp. J. 1998, 4, 77-89. [CrossRef]

11. Chua, C.K.; Hong, K.H.; Ho, S.L. Rapid tooling technology. Part 1. A comparative study. Int. J. Adv. Manuf. Technol. 1999, 15, 604-608. [CrossRef]

12. Radstok, E. Rapid tooling. Rapid Prototyp. J. 1999, 5, 164-168. [CrossRef]

13. Chua, C.K.; Hong, K.H.; Ho, S.L. Rapid tooling technology. Part 2. A case study using arc spray metal tooling. Int. J. Adv. Manuf. Technol. 1999, 15, 609-614. [CrossRef]

14. Rosochowski, A.; Matuszak, A. Rapid tooling: The state of the art. J. Mater. Process. Technol. 2000, 106, 191-198. [CrossRef]

15. Lerner, Y.; Rao, P.N.; Kouznetsov, V. Rapid tooling in metalcasting. Foundry Manag. Technol. (USA) 2002, $130,47$.

16. Hopkinson, N.; Hague, R.J.M.; Dickens, P.M. Rapid Manufacturing: An Industrial Revolution for the Digital Age; John Wiley and Sons, Ltd.: Chichister, UK, 2006.

17. Pham, D.T.; Dimov, S.S. Rapid prototyping and rapid tooling-The key enablers for rapid manufacturing. Proc. Inst. Mech. Eng. Part C J. Mech. Eng. Sci. 2003, 217, 1-24. [CrossRef]

18. Levy, G.N.; Schindel, R.; Kruth, J.P. Rapid manufacturing and rapid tooling with layer manufacturing (LM) technologies, state of the art and future perspectives. CIRP Ann. 2003, 52, 589-609. [CrossRef]

19. Lee, C.W.; Chua, C.K.; Cheah, C.M.; Tan, L.H.; Feng, C. Rapid investment casting: Direct and indirect approaches via fused deposition modelling. Int. J. Adv. Manuf. Technol. 2004, 23, 93-101. [CrossRef]

20. Cheah, C.M.; Chua, C.K.; Lee, C.W.; Feng, C.; Totong, K. Rapid prototyping and tooling techniques: A review of applications for rapid investment casting. Int. J. Adv. Manuf. Technol. 2005, 25, 308-320. [CrossRef]

21. Hopkinson, N.; Dickens, P. Rapid prototyping for direct manufacture. Rapid Prototyp. J. 2001, 7, 197-202. [CrossRef]

22. Bak, D. Rapid prototyping or rapid production? 3D printing processes move industry towards the latter. Assem. Autom. 2003, 23, 340-345. [CrossRef]

23. Hopkinson, N.; Dicknes, P. Analysis of rapid manufacturing-Using layer manufacturing processes for production. Proc. Inst. Mech. Eng. Part C J. Mech. Eng. Sci. 2003, 217, 31-39. [CrossRef]

24. Yan, Y.; Li, S.; Zhang, R.; Lin, F.; Wu, R.; Lu, Q.; Xiong, Z.; Wang, X. Rapid Prototyping and Manufacturing Technology: Principle, Representative Technics, Applications, and Development Trends. Tsinghua Sci. Technol. 2009, 14, 1-12. [CrossRef]

25. Ballardini, R.M.; Flores Ituarte, I.; Pei, E. Printing spare parts through additive manufacturing: Legal and digital business challenges. J. Manuf. Technol. Manag. 2018, 29, 958-982. [CrossRef]

26. Fomlabs Form 1. Available online: https://makezine.com/2013/11/08/formlabs-form-1/ (accessed on 8 May 2019).

27. Prusa, J. Introducing Original Prusa SL1—Open Source SLA 3D Printer by Josef Prusa. Available online: https:// blog.prusaprinters.org/introducing-original-prusa-sl1-open-source-sla-3d-printer-by-josef-prusa/ (accessed on 8 May 2019). 
28. Ragan, S.M. Homemade High Resolution DLP 3D Printer. Available online: https://makezine.com/2010/10/ 15/homemade-high-resolution-dlp-3d-pri/ (accessed on 8 May 2019).

29. Shultz, M. Formlabs Announces Desktop SLS Printer, Automated Manufacturing System. Available online: https://makezine.com/2017/06/05/formlabs-fuse-1-form-cell/ (accessed on 8 May 2019).

30. Jones, R.; Haufe, P.; Sells, E.; Iravani, P.; Olliver, V.; Palmer, C.; Bowyer, A. RepRap-the Replicating Rapid Prototyper. Robotica 2011, 29, 177-191. [CrossRef]

31. Bowyer, A. 3D Printing and Humanity's First Imperfect Replicator. 3D Print. Addit. Manuf. 2014, 1, 4-5. [CrossRef]

32. Rayna, T.; Striukova, L. From rapid prototyping to home fabrication: How 3D printing is changing business model innovation. Technol. Forecast. Soc. Chang. 2016, 102, 214-224. [CrossRef]

33. Laplume, A.; Anzalone, G.; Pearce, J. Open-source, self-replicating 3-D printer factory for small-business manufacturing. Int. J. Adv. Manuf. Technol. 2015, 85, 633-642. [CrossRef]

34. Laplume, A.; Petersen, B.; Pearce, J. Global value chains from a 3D printing perspective. J. Int. Bus. Stud. 2016, 47, 595-609. [CrossRef]

35. Gershenfeld, N. How to make almost anything. Foreign Aff. 2012, 91, 43-57.

36. Gwamuri, J.; Wittbrodt, B.; Anzalone, N.; Pearce, J. Reversing the Trend of Large Scale and Centralization in Manufacturing: The Case of Distributed Manufacturing of Customizable 3-D-Printable Self-Adjustable Glasses. Chall. Sustain. 2014, 2, 30-40. [CrossRef]

37. Wittbrodt, B.; Laureto, J.; Tymrak, B.; Pearce, J. Distributed Manufacturing with 3-D Printing: A Case Study of Recreational Vehicle Solar Photovoltaic Mounting Systems. J. Frugal Innov. 2015, 1, 1-7. [CrossRef]

38. Woern, A.L.; Pearce, J.M. Distributed Manufacturing of Flexible Products: Technical Feasibility and Economic Viability. Technologies 2017, 5, 71. [CrossRef]

39. Woern, A.L.; Byard, D.J.; Oakley, R.B.; Fiedler, M.J.; Snabes, S.L.; Pearce, J.M. Fused Particle Fabrication 3-D Printing: Recycled Materials' Optimization and Mechanical Properties. Materials 2018, 11, 1413. [CrossRef] [PubMed]

40. Reich, M.J.; Woern, A.L.; Tanikella, N.G.; Pearce, J.M. Mechanical Properties and Applications of Recycled Polycarbonate Particle Material Extrusion-Based Additive Manufacturing. Materials 2019, 12, 1642. [CrossRef] [PubMed]

41. Shih, C.C.; Burnette, M.; Staack, D.; Wang, J.; Tai, B.L. Effects of cold plasma treatment on interlayer bonding strength in FFF process. Addit. Manuf. 2019, 25, 104-111. [CrossRef]

42. Go, J.; Hart, A.J. Fast desktop-scale extrusion additive manufacturing. Addit. Manuf. 2017, 18, $276-284$. [CrossRef]

43. Ravi, A.K.; Deshpande, A.; Hsu, K.H. An in-process laser localized pre-deposition heating approach to inter-layer bond strengthening in extrusion based polymer additive manufacturing. J. Manuf. Process. 2016, 24, 179-185. [CrossRef]

44. Kishore, V.; Ajinjeru, C.; Nycz, A.; Post, B.; Lindahl, J.; Kunc, V.; Duty, C. Infrared preheating to improve interlayer strength of big area additive manufacturing (BAAM) components. Addit. Manuf. 2017, 14, 7-12. [CrossRef]

45. Lederle, F.; Meyer, F.; Brunotte, G.P.; Kaldun, C.; Hübner, E.G. Improved mechanical properties of 3D-printed parts by fused deposition modeling processed under the exclusion of oxygen. Prog. Addit. Manuf. 2016, 1, 3-7. [CrossRef]

46. Abourayana, H.; Dobbyn, P.; Dowling, D. Enhancing the mechanical performance of additive manufactured polymer components using atmospheric plasma pre-treatments. Plasma Process. Polym. 2018, 15, 1700141. [CrossRef]

47. Shaffer, S.; Yang, K.; Vargas, J.; Di Prima, M.A.; Voit, W. On reducing anisotropy in 3D printed polymers via ionizing radiation. Polymer 2014, 55, 5969-5979. [CrossRef]

48. Sweeney, C.B.; Lackey, B.A.; Pospisil, M.J.; Achee, T.C.; Hicks, V.K.; Moran, A.G.; Green, M.J. Welding of 3D-printed carbon nanotube-polymer composites by locally induced microwave heating. Sci. Adv. 2017, 3, e1700262. [CrossRef] [PubMed]

49. Li, G.; Zhao, J.; Wu, W.; Jiang, J.; Wang, B.; Jiang, H.; Fuh, J. Effect of ultrasonic vibration on mechanical properties of $3 \mathrm{~d}$ printing non-crystalline and semi-crystalline polymers. Materials 2018, 11, 826. [CrossRef] [PubMed] 
50. Tofangchi, A.; Han, P.; Izquierdo, J.; Iyengar, A.; Hsu, K. Effect of Ultrasonic Vibration on Interlayer Adhesion in Fused Filament Fabrication 3D Printed ABS. Polymers 2019, 11, 315. [CrossRef] [PubMed]

51. Hart, K.R.; Dunn, R.M.; Sietins, J.M.; Mock, C.M.H.; Mackay, M.E.; Wetzel, E.D. Increased fracture toughness of additively manufactured amorphous thermoplastics via thermal annealing. Polymer 2018, 144, 192-204. [CrossRef]

52. Singh, S.; Singh, M.; Prakash, C.; Gupta, M.K.; Mia, M.; Singh, R. Optimization and reliability analysis to improve surface quality and mechanical characteristics of heat-treated fused filament fabricated parts. Int. J. Adv. Manuf. Technol. 2019, 102, 1-16. [CrossRef]

53. Tanikella, N.G.; Wittbrodt, B.; Pearce, J.M. Tensile strength of commercial polymer materials for fused filament fabrication 3D printing. Addit. Manuf. 2017, 15, 40-47. [CrossRef]

54. Wu, W.; Geng, P.; Li, G.; Zhao, D.; Zhang, H.; Zhao, J. Influence of layer thickness and raster angle on the mechanical properties of 3D-printed PEEK and a comparative mechanical study between PEEK and ABS. Materials 2015, 8, 5834-5846. [CrossRef]

55. Xiaoyong, S.; Liangcheng, C.; Honglin, M.; Peng, G.; Zhanwei, B.; Cheng, L. Experimental analysis of high temperature PEEK materials on 3D printing test. In Proceedings of the 2017 9th International Conference on Measuring Technology and Mechatronics Automation (ICMTMA), Changsha, China, 14-15 January 2017. [CrossRef]

56. Ning, F.; Cong, W.; Hu, Y.; Wang, H. Additive manufacturing of carbon fiber-reinforced plastic composites using fused deposition modeling: Effects of process parameters on tensile properties. J. Compos. Mater. 2017, 51, 451-462. [CrossRef]

57. Lu, Y.; Poh, G.K.; Gleadall, A.; Zhao, L.; Han, X. Fabrication of the continuous carbon fiber reinforced plastic composites by additive manufacturing. In Proceedings of the 16th Conference on Rapid Design, Prototyping \& Manufacturing (RDPM2019), London, UK, 4-5 April 2019.

58. Caminero, M.Á.; Chacón, J.M.; García-Plaza, E.; Núñez, P.J.; Reverte, J.M.; Becar, J.P. Additive Manufacturing of PLA-Based Composites Using Fused Filament Fabrication: Effect of Graphene Nanoplatelet Reinforcement on Mechanical Properties, Dimensional Accuracy and Texture. Polymers 2019, 11, 799. [CrossRef]

59. Levenhagen, N.P.; Dadmun, M.D. Interlayer diffusion of surface segregating additives to improve the isotropy of fused deposition modeling products. Polymer 2018, 152, 35-41. [CrossRef]

60. Levenhagen, N.P.; Dadmun, M.D. Improving Interlayer Adhesion in 3D Printing with Surface Segregating Additives: Improving the Isotropy of Acrylonitrile-Butadiene-Styrene Parts. ACS Appl. Polym. Mater. 2019, 1, 876-884. [CrossRef]

61. Kuznetsov, V.E.; Solonin, A.N.; Urzhumtsev, O.D.; Schilling, R.; Tavitov, A.G. Strength of PLA Components Fabricated with Fused Deposition Technology Using a Desktop 3D Printer as a Function of Geometrical Parameters of the Process. Polymers 2018, 10, 313. [CrossRef] [PubMed]

62. Kuznetsov, V.E.; Solonin, A.N.; Tavitov, A.G.; Urzhumtsev, O.D.; Vakulik, A.H. Increasing of Strength of FDM (FFF) 3D Printed Parts by Influencing on Temperature-Related Parameters of the Process. Preprints 2018. [CrossRef]

63. Kuznetsov, V.E.; Tavitov, A.G.; Urzhumtcev, O.D. Hardware Factors Influencing Interlayer Bonding Strength of Parts Obtained by Fused Filament Fabrication. Preprints 2019. [CrossRef]

64. Kuznetsov, V.E.; Tavitov, A.G.; Urzhumtsev, O.D.; Mikhalin, M.V.; Solonin, A.N. Design and Fabrication of Strong Parts from Poly (Lactic Acid) with a Desktop 3D Printer: A Case with Interrupted Shell. Polymers 2019, 11, 760. [CrossRef] [PubMed]

65. Cura 15.0x branch. Available online: https://github.com/daid/LegacyCura (accessed on 8 May 2019).

66. Download FLIR Tools. Available online: https://www.flir.com/products/flir-tools/ (accessed on 8 May 2019).

67. Enblend/Enfuse—Combine Images with No Fuse. Available online: http://enblend.sourceforge.net (accessed on 8 May 2019).

68. Tweak at Z Plugin for Cura 15.xx. Available online: https:/github.com/daid/LegacyCura/blob/SteamEngine/ plugins/TweakAtZ.py (accessed on 8 May 2019).

(C) 2019 by the authors. Licensee MDPI, Basel, Switzerland. This article is an open access article distributed under the terms and conditions of the Creative Commons Attribution (CC BY) license (http://creativecommons.org/licenses/by/4.0/). 